\title{
A Framework to Report the Production of Renewable Diesel from Algae
}

\author{
Colin M. Beal • Colin H. Smith • Michael E. Webber • \\ Rodney S. Ruoff • Robert E. Hebner
}

Published online: 12 August 2010

(C) The Author(s) 2010. This article is published with open access at Springerlink.com

\begin{abstract}
Recently, algae have received significant interest as a potential feedstock for renewable diesel (such as biodiesel), and many researchers have attempted to quantify this potential. Some of these attempts are less useful because they have not incorporated specific values of algal lipid content, have not included processing inefficiencies, or omitted processing steps required for renewable diesel production. Furthermore, the associated energy, materials, and costs requirements are sometimes omitted. The accuracy and applicability of these estimates can be improved by using data that are more specific, including all relevant information for renewable diesel production, and by presenting information with more relevant metrics. To determine whether algae are a viable source for renewable
\end{abstract}

See Appendix 1 for a complete list of symbols

C. M. Beal • C. H. Smith • M. E. Webber $(\bowtie) \cdot$ R. S. Ruoff •

R. E. Hebner

Department of Mechanical Engineering,

Cockrell School of Engineering,

The University of Texas at Austin,

1 University Station C2200,

Austin, TX 78712, USA

e-mail: webber@mail.utexas.edu

M. E. Webber

Center for International Energy and Environmental Policy,

The University of Texas at Austin,

Austin, TX 78712, USA

R. S. Ruoff

The Texas Materials Institute, The University of Texas at Austin,

Austin, TX 78712, USA

R. E. Hebner

The Center for Electromechanics,

The University of Texas at Austin,

Austin, TX 78712, USA diesel, three questions that must be answered are (1) how much renewable diesel can be produced from algae, (2) what is the financial cost of production, and (3) what is the energy ratio of production? To help accurately answer these questions, we propose an analytical framework and associated nomenclature system for characterizing renewable diesel production from algae. The three production pathways discussed in this study are the transesterification of extracted algal lipids, thermochemical conversion of algal biomass, and conversion of secreted algal oils. The nomenclature system is initially presented from a top-level perspective that is applicable to all production pathways for renewable diesel from algae. Then, the nomenclature is expanded to characterize the production of renewable diesel (specifically, biodiesel) from extracted algal lipids in detail (cf. Appendix 2). The analytical framework uses the presented nomenclature system and includes three main principles: using appropriate reporting metrics, using symbolic notation to represent unknown values, and presenting results that are specific to algal species, growth conditions, and product composition.

Keywords Renewable diesel - Biodiesel - Algae · Reporting framework $\cdot$ Systems analysis $\cdot$ Lipid

\begin{tabular}{|c|c|}
\hline $\begin{array}{l}\text { Abbre } \\
\text { Gener }\end{array}$ & iations \\
\hline FROI & Financial return on \\
\hline EROI & Energy return on \\
\hline LHV & Lower heating valu \\
\hline Produ & \\
\hline $\mathrm{RD}$ & Renewable diesel \\
\hline $\mathrm{BD}$ & Biodiesel \\
\hline $\mathrm{BC}$ & Biocrude \\
\hline
\end{tabular}




$\begin{array}{ll}\text { GM } & \text { Grown mass } \\ \text { HM } & \text { Harvested mass } \\ \text { LM } & \text { Lysed mass } \\ \text { L } & \text { Lipids } \\ \text { SL } & \text { Separated lipids } \\ \text { UL } & \text { Useful lipids } \\ \text { SUL } & \text { Separated useful lipids } \\ \text { FAME } & \text { Fatty acid methyl ester } \\ \text { TAG } & \text { Triacylglycerol }\end{array}$

Processes

G Growth

P Processing

R Refining

$\mathrm{H} \quad$ Harvesting

CL Cell lysing

S Separations

T Transesterification

PP Post-processing $\widetilde{c}$

C

c

$\widetilde{E}$

$\widetilde{e}$

E

$e$

FROI

EROI

$\rho$
Cost for a processing step (in units of dollars per kilogram of product)

Cost of intermediate product (in units of dollars per liter of renewable diesel)

Cost of intermediate product (in units of dollars per kilogram of product)

$\widetilde{E} \quad$ Energy requirement for a processing step (in units of joules per liter of renewable diesel)

Energy requirement for a processing step (in units of joules per kilogram of product)

E Energy requirement for intermediate product (in units of joules per liter of renewable diesel)

Energy requirement for intermediate product (in units of joules per kilogram of product)

Financial return on investment

Energy return on (energy) investment

Density

\section{Introduction}

\section{Overview}

Currently, there is a global effort to develop alternative transportation fuels. Dozens of biological feedstock sources have been suggested to meet this effort, and the success of their implementation has varied. In this paper, we discuss algal oil, which has been touted as a potential feedstock for renewable diesel production. Specifically, we present a framework for reporting renewable diesel production from algae. Algae are an extremely diverse group of organisms, and it is not surprising that different species of algae produce different compounds that could be used as alternative fuel feedstock. Five commonly studied algal components or products useful for alternative fuels are: lipids for petroleum fuel substitutes, carbohydrates for ethanol, hydrogen, methane via biomass gasification, and biomass for direct combustion, anaerobic digestion, or thermochemical conversion [1-10]. The conversion pathways that are available (i.e., biochemical conversion, thermochemical conversion, and transesterification) for producing algae-based fuel (e.g., biodiesel, methane, hydrogen, electricity, etc.) have been outlined [11, 12]. The framework presented here is focused on characterizing the production of renewable diesel from algae. The term, "renewable diesel" is defined as a substitute for conventional diesel fuel that is derived from renewable resources (e.g., biodiesel) [13-15]. Renewable diesel fuels are produced by upgrading a renewable oil material, which is referred to as biocrude, and can be produced from a variety of feedstock and production pathways. It is possible that non-diesel fuels could be produced from algal biocrude by

Nomenclature

$P \quad$ Productivity

$M \quad$ Mass

$V \quad$ Volume

$t_{\mathrm{c}} \quad$ Cultivation time

$\varphi \quad$ Efficiency

$\widetilde{C} \quad$ Cost for a processing step (in units of dollars per liter of renewable diesel) 
alternative refining techniques. Although this study presents a framework for reporting the production of renewable diesel fuel from algae, it is expected that similar methods can be used to report other algal fuels.

The use of algae for alternative fuels has been studied globally by researchers for several decades. The United States' National Renewable Energy Laboratory conducted an 18-year research effort, the Aquatic Species Program, which investigated the use of algae for biodiesel [1]. Dozens of other research and industry groups have conducted algae-to-biofuel studies during the time of the Aquatic Species Program and since its conclusion in 1996.

There are multiple production pathways that are being researched for renewable diesel production from algae. Categorically, these include (1) transesterification of extracted algal lipids, (2) thermochemical conversion of algal biomass, and (3) conversion of secreted algal oils (i.e., "milking"). Each of these pathways is discussed in greater detail in the following sections. The reporting framework presented here provides a way to compare results, not only from within the same production pathway, but also among different production pathways.

In general, the potential of algae-derived renewable diesel to be a suitable alternative fuel is dependent on the answers to three questions: (1) how much renewable diesel can be produced, (2) what is the financial cost of production, and (3) what is the energy ratio of producing renewable diesel? In this study, the amount of renewable diesel that can be produced is evaluated with respect to the cultivation volume and growth duration and is therefore expressed in units of grams per liter per day. Different metrics could be used for evaluating the amount of renewable diesel that can be produced on a national or global scale, such as the total land, water, and nutrients required to produce enough renewable diesel to satisfy the US liquid fuel demand. In addition, evaluating the amount of renewable diesel that can be produced at the national or global level requires the consideration of other factors, such as environmental impacts, resource availability, and infrastructure renovations, which are not specifically addressed in this study. However, the three questions listed above are critical for evaluating the potential of an alternative fuel to make a significant contribution to energy supply. Many variables influence the evaluation of each of these questions, and it is important to establish a systematic approach to determine the answers.

Although great progress has been made regarding the use of algae for renewable diesel, the field is relatively young. Consequently, some ambiguity remains about the best way to report research results. In turn, it is easy to misinterpret published results because the nomenclature varies. Furthermore, because an explicit reporting method has not been established, researchers are at risk of inaccurately estimating the potential for algae as a renewable diesel feedstock by accidentally omitting important processing inefficiencies. Finally, due to the lack of standardization, it is difficult for researchers to integrate results from multiple sources. The following section illuminates the inconsistencies discussed here.

\section{Reporting Variability and Inconsistency}

The advantages of a particular species, growth environment, or conversion technology depend on the impact it has on the entire production pathway. Said differently, the fundamental interest is in the total energy, materials, and cost balances for renewable diesel production. To enable systems-level analyses, when reporting results associated with individual processing steps (e.g., growth, harvesting, refining, etc.), it would be ideal to use metrics that are compatible with the other steps. Using compatible metrics is also important, but more complicated, if renewable diesel production from algae is integrated into a multi-product facility, in which waste streams of one product are used for another. Multi-product industrial facilities like this are not specifically considered in this study.

To illustrate the variability in reporting methods, Tables 1 and 2 list results from several algae-based renewable diesel studies pertaining to how much renewable diesel can be produced and the financial cost of production. The data presented are specific to the production of biodiesel via transesterification of extracted lipids (as opposed to the other production pathways, all of which are discussed below). Each symbol listed in Tables 1 and 2 (e.g., $P_{\mathrm{GM}}$, $\varphi_{\text {sep }}, \widetilde{C}_{T}$, etc.) is defined in Appendix 1 and discussed in more detail in the following sections (cf. Figs. 2 and 7). These tables illustrate the variety of reporting methods used in the field, but do not encompass or represent all algaebased renewable diesel research that has been published. For most categories shown, there is a wide range of results. For instance, the estimated cost of producing algal "oil" (or lipids) varies from $\$ 39$ to $\$ 209$ per barrel across the studies. Additionally, there are different metrics used to report results within the same category. For example, biomass productivity is commonly reported in terms of kilograms per square meter per day or kilograms per liter per day (where square meter is for the growth media surface area and liter is for the growth media volume), which can lead to ambiguities [41]. Both metrics can provide valuable data, and both should be reported when possible. In addition, some studies use metrics to report results that do not include enough information to adequately characterize the potential of algae as a renewable diesel feedstock. For example, the lipid fraction is often used to evaluate the potential of different algal species $[1,16,21,41]$. As discussed below, the lipid fraction lacks the specificity needed to evaluate the impact of that species, growth condition, and type of lipids 


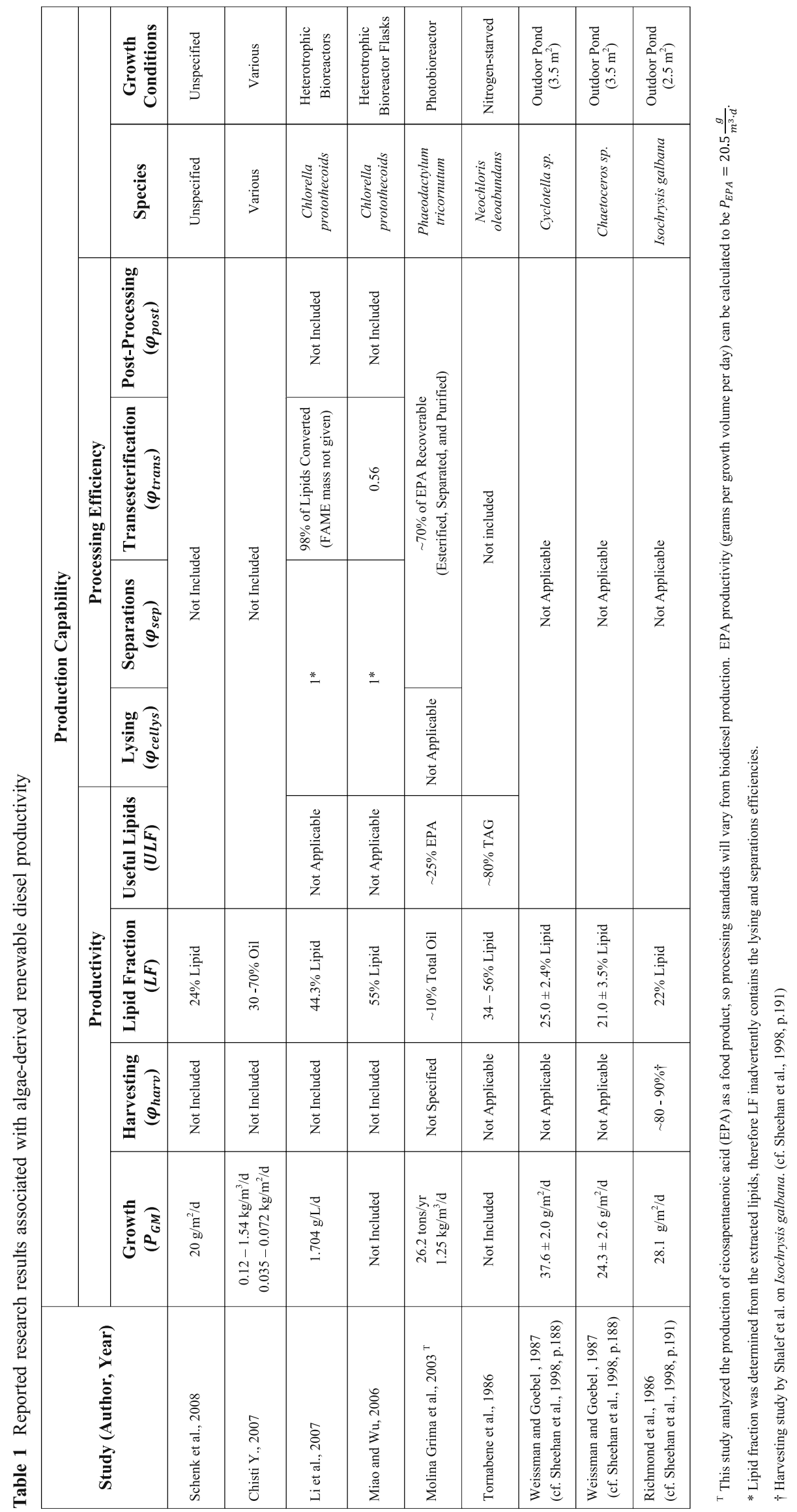




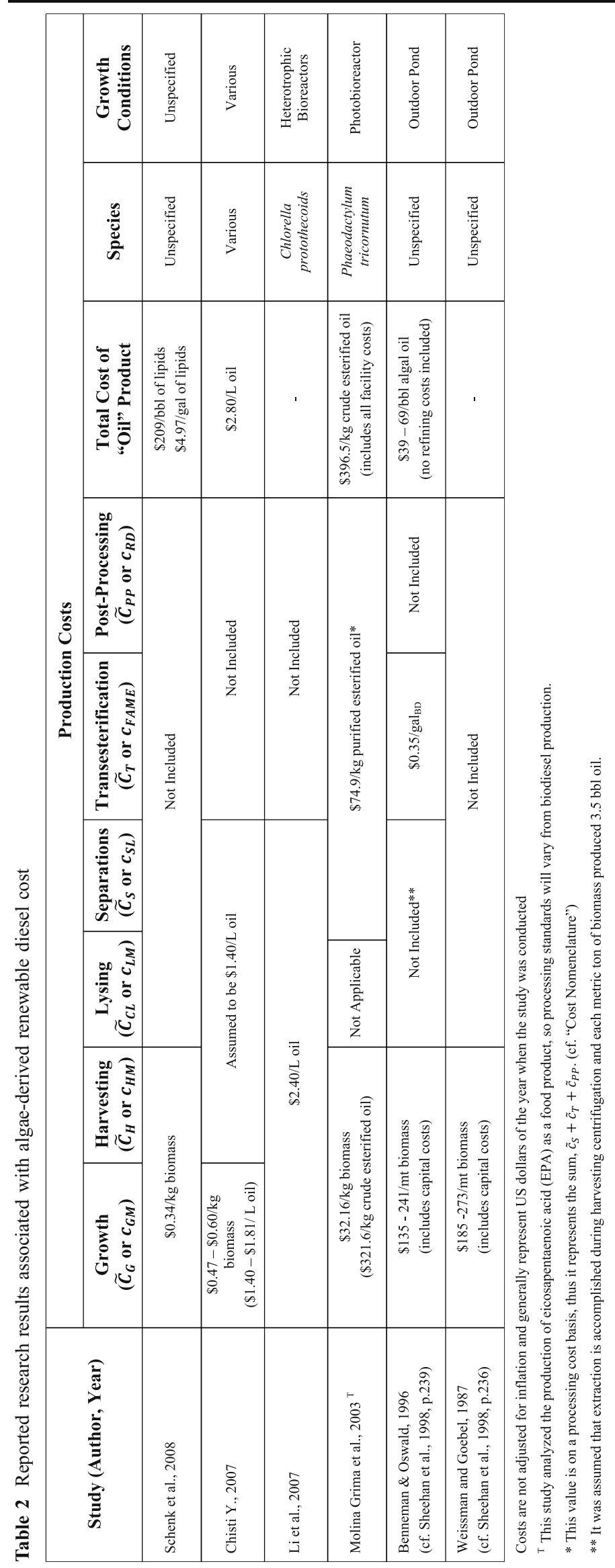


produced on the entire production pathway [41]. Finally, in most of the studies shown, several steps in the production pathway are omitted entirely.

Due to these inconsistencies, it is difficult to accurately determine the potential of algae-derived renewable diesel on a systems level. Additional standardization is needed within the field so that communication among researchers is less ambiguous. To address this problem, we outline three production pathways for algae-derived renewable diesel, present a nomenclature system for reporting results, and propose a framework for characterizing the potential of algae as a source for renewable diesel production. The nomenclature system is presented as a top-level analysis that is applicable to all three of the production pathways. The utility of this nomenclature system is illustrated in Appendix 2 by expanding it to include the detailed production steps for one of the production pathways (namely, transesterification of extracted algal lipids). A detailed expansion of the other production pathways (thermochemical conversion of algal biomass and conversion of secreted algal oils) can be conducted similarly.

\section{Top-Level Algae-Derived Renewable Diesel Production Pathway}

This section presents the top-level nomenclature system for reporting productivity, cost, and energy requirements for producing algae-derived renewable diesel, all of which are based on the production pathway flow diagram in Fig. 1. The nomenclature system is necessary for reporting results within the analytical framework that is subsequently presented.

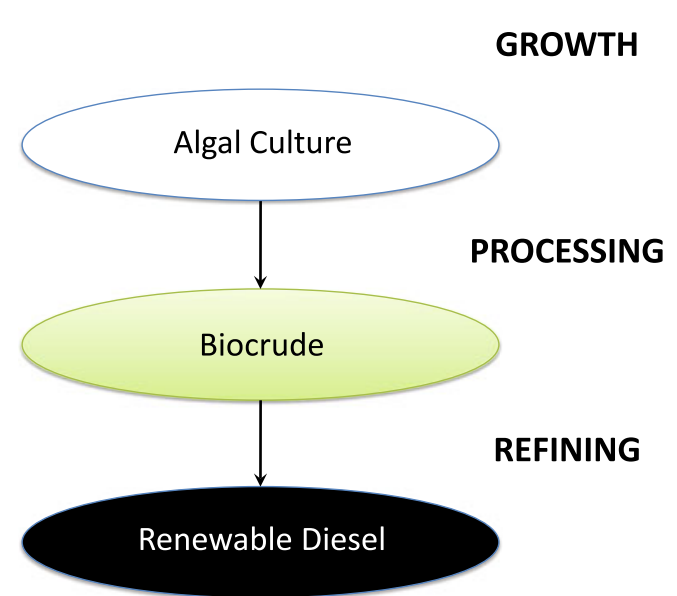

Fig. 1 Renewable biodiesel production can be represented in simplified form as three phases: growth, processing, and refining
Productivity

First, the renewable diesel productivity, $P_{\mathrm{RD}}$, can be written as

$$
P_{\mathrm{RD}}=\frac{M_{\mathrm{RD}}}{V_{\mathrm{G}} \cdot t_{\mathrm{c}}}=P_{\mathrm{GM}} \cdot \varphi_{\text {proc }} \cdot \varphi_{\text {ref }} \quad\left[\frac{\mathrm{g}}{\mathrm{L}_{\mathrm{G}} \cdot \text { day }}\right]
$$

where $M_{\mathrm{RD}}$ is the mass of renewable diesel produced, $V_{\mathrm{G}}$ is the algal growth volume, $t_{\mathrm{c}}$ is the cultivation period, and $P_{\mathrm{GM}}$ is the grown (algal) mass productivity (g of dry algal biomass/(L-day)). In this proposed nomenclature system, "productivity" is a volumetric measure, based on the growth volume $\left(V_{\mathrm{G}}\right)$. Although areal productivity is important for many studies $[9,12,42-44]$, to determine how much renewable diesel can be produced, volumetric productivity is also a critical measure. It is important to specify the dry weight measurement method used, and it is best to measure organic dry weight (i.e., by removing inorganic solids). The processing efficiency, $\varphi_{\text {proc }}$, can be defined as the mass of biocrude, $M_{\mathrm{BC}}$, that is obtained by a processing method divided by the amount of (dry) grown mass, $M_{\mathrm{GM}}$, that was present in the growth medium prior to processing (g biocrude/g grown mass), as shown in Eq. 2. The dry grown mass is calculated as the algal concentration $(\mathrm{g} / \mathrm{L})$ multiplied by the growth volume (L).

$$
\varphi_{\text {proc }}=\frac{M_{\mathrm{BC}}}{M_{\mathrm{GM}}} \quad[-]
$$

The refining efficiency, $\varphi_{\text {ref }}$, is defined as the amount of renewable diesel, $M_{\mathrm{RD}}$, that is produced from an associated amount of biocrude, $M_{\mathrm{BC}}$, which can be expressed as

$$
\varphi_{\text {ref }}=\frac{M_{\mathrm{RD}}}{M_{\mathrm{BC}}} \quad[-]
$$

\section{Cost}

A similar top-level cost analysis of algae-derived renewable diesel production can also be created. The cost of renewable diesel, $C_{\mathrm{RD}}$, can be written as

$$
C_{\mathrm{RD}}=c_{\mathrm{RD}} \cdot \rho_{\mathrm{RD}}=\widetilde{C}_{\mathrm{G}}+\widetilde{C}_{\mathrm{P}}+\widetilde{C}_{\mathrm{R}} \quad\left[\frac{\$}{\mathrm{LDD}_{\mathrm{DD}}}\right]
$$

where $\widetilde{C}_{\mathrm{G}}, \widetilde{C}_{\mathrm{P}}$, and $\widetilde{C}_{\mathrm{R}}$ are the cost of growth, processing, and refining, in dollars per liter of renewable diesel. A tilde $(\sim)$ is used to differentiate the cost of a production step (i.e., growth, processing, or refining), from the cost of a product (i.e., grown mass, biocrude, or renewable diesel). In Eq. 4, $c_{\mathrm{RD}}$ is the cost of producing renewable diesel per kilogram of renewable diesel, where the lowercase " $c$ " denotes a cost on a per mass basis. Thus, the product of $c_{R D}$ and the density of renewable diesel, $\rho_{\mathrm{RD}}$, is equal to the cost of 
producing renewable diesel per liter. The units used in Eq. 4 are adopted because many products are priced by volume, rather than by mass.

Each cost on the right-hand side of Eq. 4 can be expanded. For instance, the cost of growing algal biomass, $\widetilde{C}_{\mathrm{G}}$, can be expanded as

$\widetilde{C}_{\mathrm{G}}=\widetilde{c}_{\mathrm{G}} \cdot \mathrm{GMCF} \cdot \rho_{\mathrm{RD}} \quad\left[\frac{\$}{\mathrm{~L}_{\mathrm{RD}}}\right]$

In Eq. $5, \widetilde{c}_{\mathrm{G}}$ is the cost of growing algal biomass, in dollars per kilogram of (dry) grown mass, and $\rho_{\mathrm{RD}}$ is the density of renewable diesel. GMCF is the grown mass conversion factor, which is the amount of dry biomass that must be grown in order to produce an associated mass of renewable diesel. Conversion factors, such as GMCF, are dependent upon the subsequent production efficiencies, and the GMCF is defined as

$\mathrm{GMCF}=\frac{1}{\varphi_{\text {proc }}}\left[\frac{\mathrm{kg}_{\mathrm{GM}}}{\mathrm{kg}_{\mathrm{BC}}}\right] \cdot \frac{1}{\varphi_{\text {ref }}}\left[\frac{\mathrm{kg}_{\mathrm{BC}}}{\mathrm{kg}_{\mathrm{RD}}}\right]$

The cost of the processing phase, $\widetilde{C}_{\mathrm{P}}$, in dollars per liter of renewable diesel can likewise be expanded as

$\widetilde{C}_{\mathrm{P}}=\widetilde{c}_{\mathrm{P}} \cdot \mathrm{BCCF} \cdot \rho_{\mathrm{RD}} \quad\left[\frac{\$}{\mathrm{~L}_{\mathrm{RD}}}\right]$

where $\widetilde{c}_{\mathrm{P}}$ is the cost of the processing phase in dollars per kilogram of biocrude and BCCF is the biocrude conversion factor, which is defined as

$\mathrm{BCCF}=\frac{1}{\varphi_{\text {ref }}} \quad\left[\frac{\mathrm{kg}_{\mathrm{BC}}}{\mathrm{kg}_{\mathrm{RD}}}\right]$

Finally, the refining cost can be expressed as

$\widetilde{C}_{\mathrm{R}}=\widetilde{c}_{\mathrm{R}} \cdot \rho_{\mathrm{RD}} \quad\left[\frac{\$}{L_{\mathrm{RD}}}\right]$

where $\widetilde{c}_{R}$ is the cost of refining in dollars per kilogram of refined product (i.e., renewable diesel).
It may also be useful to report cost results on a mass basis. The products of the production phases are grown mass, biocrude, and renewable diesel. The cost of producing these products can be expressed as shown in Table 3. Two expressions for the cost of producing renewable diesel on a mass basis $(\$ / \mathrm{kg}$ of renewable diesel) are also included in Table 3. The financial return on investment, $\mathrm{FROI}_{\mathrm{RD}}$, can be expressed as

$$
\mathrm{FROI}_{\mathrm{RD}}=\frac{R_{\mathrm{RD}}+R_{\mathrm{CP}}}{C_{\mathrm{RD}}} \quad[-]
$$

where $R_{\mathrm{RD}}$ is the revenue generated by renewable diesel, $R_{\mathrm{CP}}$ is the revenue generated from co-products, and $C_{\mathrm{RD}}$ is the cost of producing renewable diesel. Each of these terms is measured in units of dollars per liter per day; however, the units could be adjusted for batch processing as needed. If additional processing is required for co-products (e.g., converting the biomass co-product to fuels or chemicals), the associated processing costs should be included in the denominator of Eq. 10.

Equations $4,5,6,7,8,9$, and those listed in Table 3 demonstrate the difference between the cost of production steps, which are denoted with a tilde (e.g., cost of growth, $\widetilde{c}_{\mathrm{G}}$ ), and the cost of products, which do not include a tilde (e.g., the cost of grown mass, $c_{\mathrm{GM}}$ ).

\section{Energy}

It is important to determine the financial cost and the energy ratio associated with producing renewable diesel from algae. In general, the financial and energy costs should be directly related. However, the economics of energy production includes many variables that can skew this relationship $[45,46]$. The energy required to produce renewable diesel (direct and indirect), $E_{\mathrm{RD}}$, in joules per liter, can be calculated as

$$
E_{\mathrm{RD}}=e_{\mathrm{RD}} \cdot \rho_{\mathrm{RD}}=\widetilde{E}_{\mathrm{G}}+\widetilde{E}_{\mathrm{P}}+\widetilde{E}_{\mathrm{R}} \quad\left[\frac{\mathrm{J}}{\mathrm{L}_{\mathrm{RD}}}\right]
$$

\begin{tabular}{|c|c|c|c|c|}
\hline \multirow[b]{2}{*}{ Grown mass } & \multicolumn{2}{|l|}{ Financial costs } & \multicolumn{2}{|l|}{ Energy requirements } \\
\hline & $c_{\mathrm{GM}}=\widetilde{c}_{\mathrm{G}} \quad\left[\frac{\$}{\mathrm{~kg}_{\mathrm{GM}}}\right]$ & & $e_{\mathrm{GM}}=\tilde{e}_{\mathrm{G}}\left[\frac{\mathrm{J}}{\mathrm{kg}_{\mathrm{GM}}}\right]$ & \\
\hline Biocrude & $c_{\mathrm{BC}}=c_{\mathrm{GM}} \cdot \frac{1}{\varphi_{\mathrm{proc}}}+\widetilde{c}_{\mathrm{P}} \quad\left[\frac{\$}{\mathrm{~kg}_{\mathrm{BC}}}\right]$ & & $e_{\mathrm{BC}}=e_{\mathrm{GM}} \cdot \frac{1}{\varphi_{\mathrm{proc}}}+\widetilde{e}_{\mathrm{P}} \quad\left[\frac{\mathrm{J}}{\mathrm{kg}_{\mathrm{BC}}}\right]$ & \\
\hline Renewable diesel $^{\mathrm{a}}$ & $c_{\mathrm{RD}}=c_{\mathrm{BC}} \cdot \frac{1}{\varphi_{\mathrm{ref}}}+\widetilde{c}_{\mathrm{R}} \quad\left[\frac{\$}{\mathrm{~kg}_{\mathrm{RD}}}\right]$ & & $e_{\mathrm{RD}}=e_{\mathrm{BC}} \cdot \frac{1}{\varphi_{\text {ref }}}+\widetilde{e}_{\mathrm{R}} \quad\left[\frac{\mathrm{J}}{\mathrm{kg}_{\mathrm{RD}}}\right]$ & \\
\hline Renewable diesel $^{\mathrm{a}}$ & $c_{\mathrm{RD}}=\widetilde{c}_{\mathrm{G}} \cdot \mathrm{GMCF}+\widetilde{c}_{\mathrm{P}} \cdot \mathrm{BCCF}+\widetilde{c}_{\mathrm{R}}$ & {$\left[\frac{\$}{\mathrm{~kg}_{\mathrm{RD}}}\right]$} & $e_{\mathrm{RD}}=\widetilde{e}_{\mathrm{G}} \cdot \mathrm{GMCF}+\widetilde{e}_{\mathrm{P}} \cdot \mathrm{BCCF}+\widetilde{e}_{\mathrm{R}}$ & {$\left[\frac{\mathrm{J}}{\mathrm{kg}_{\mathrm{RD}}}\right]$} \\
\hline Return on investment & $\mathrm{FROI}_{\mathrm{RD}}=\frac{R_{\mathrm{RD}}+R_{\mathrm{CP}}}{C_{\mathrm{RD}}} \quad[-]$ & & $\mathrm{EROI}_{\mathrm{RD}}=\frac{\mathrm{EC}_{\mathrm{RD}}+\mathrm{EC}_{\mathrm{CP}}}{\mathrm{E}_{\mathrm{RD}}} \quad[-]$ & \\
\hline
\end{tabular}

Table 3 Financial costs, energy requirements, and return on investment for renewable diesel production

$G M$ grown mass, $B C$ biocrude, $R D$ renewable diesel, $C P$ co-products, $G$ growth, $P$ processing, $R$ refining

${ }^{a}$ The equations listed are alternative ways to report the cost and energy requirements for renewable diesel 
where $\widetilde{E}_{\mathrm{G}}, \widetilde{E}_{\mathrm{P}}$, and $\widetilde{E}_{\mathrm{R}}$ are the energy requirements for the growth, processing, and refining production steps of renewable diesel. The energy required to produce a kilogram of renewable diesel is defined as $e_{\mathrm{RD}}$. Allocating direct and indirect energy requirements for energy production systems has been presented in previous studies [4755]. The energy required to produce renewable diesel, $E_{\mathrm{RD}}$, can be calculated using the methods described by Mulder and Hagens [47].

Each of the terms on the right-hand side of Eq. 11 can be further expanded as

$$
\begin{aligned}
& \widetilde{E}_{\mathrm{G}}=\widetilde{e}_{\mathrm{G}} \cdot \mathrm{GMCF} \cdot \rho_{\mathrm{RD}} \quad\left[\frac{\mathrm{J}}{\mathrm{L}_{\mathrm{RD}}}\right] \\
& \widetilde{E}_{\mathrm{P}}=\widetilde{e}_{\mathrm{P}} \cdot \mathrm{BCCF} \cdot \rho_{\mathrm{RD}} \quad\left[\frac{\mathrm{J}}{\mathrm{L}_{\mathrm{RD}}}\right] \\
& \widetilde{E}_{\mathrm{R}}=\widetilde{e}_{\mathrm{R}} \cdot \rho_{\mathrm{RD}} \quad\left[\frac{\mathrm{J}}{\mathrm{L}_{\mathrm{RD}}}\right]
\end{aligned}
$$

where $\widetilde{e}_{\mathrm{G}}, \widetilde{e}_{\mathrm{P}}$, and $\widetilde{e}_{\mathrm{R}}$ are the energy requirements of each production step (growth, processing, and refining) per kilogram of output product (grown mass, biocrude, and renewable diesel, respectively). As done for the financial cost of each product, the energy costs can be evaluated on a per mass basis ( $\mathrm{J} / \mathrm{kg}$ of product) as shown in Table 3.
Based on the framework by Mulder and Hagens, the second-order energy return on investment for renewable diesel, $\mathrm{EROI}_{\mathrm{RD}}$, can be defined as

$\mathrm{EROI}_{\mathrm{RD}}=\frac{\mathrm{EC}_{\mathrm{RD}}+\mathrm{EC}_{\mathrm{CP}}}{E_{\mathrm{RD}}}=\frac{\mathrm{LHV} \cdot \rho_{\mathrm{RD}}+\mathrm{EC}_{\mathrm{CP}}}{E_{\mathrm{RD}}} \quad[-]$

where $\mathrm{EC}_{\mathrm{RD}}$ is the energy content of renewable diesel, $\mathrm{EC}_{\mathrm{CP}}$ is the energy content of co-products, and $E_{\mathrm{RD}}$ is the energy required (direct and indirect) to produce renewable diesel. Also in Eq. 15, LHV is the lower heating value of renewable diesel $(\mathrm{J} / \mathrm{kg})$, and $\rho_{\mathrm{RD}}$ is the renewable diesel density $(\mathrm{kg} / \mathrm{L})$. If additional energy is required to produce the final form coproducts, this energy requirement should be included in the denominator of Eq. 15.

\section{Production Pathways}

The three production pathways listed above are presented in more detail in this section and displayed in Figs. 2, 3, and 4. Within each pathway diagram, several different technology options are listed for each conversion process to advance from one level of a production pathway to the next. More research is needed to identify the most advantageous technology for each conversion step. Also, different algal species may require different conversion technology choices. Therefore, the selection of algal species and efficient processing technologies for renewable diesel production are inter-related.
Fig. 2 The production of algal biodiesel via transesterification of algal lipids contains several steps, and each step can be accomplished with various technologies. ${ }^{\dagger}$ Mechanical damage includes French press, bead beater, mortar and pestle, etc. *At this resolution, it is not clear which lipids will be useful for biodiesel production; therefore, these lipids could be an assortment or of a single type. $* *$ Biodiesel is a type of renewable diesel. $a$ [20, 23-28], $b$ [11, 29-34], $c[27,31,35], d[27,33$, 36-40]

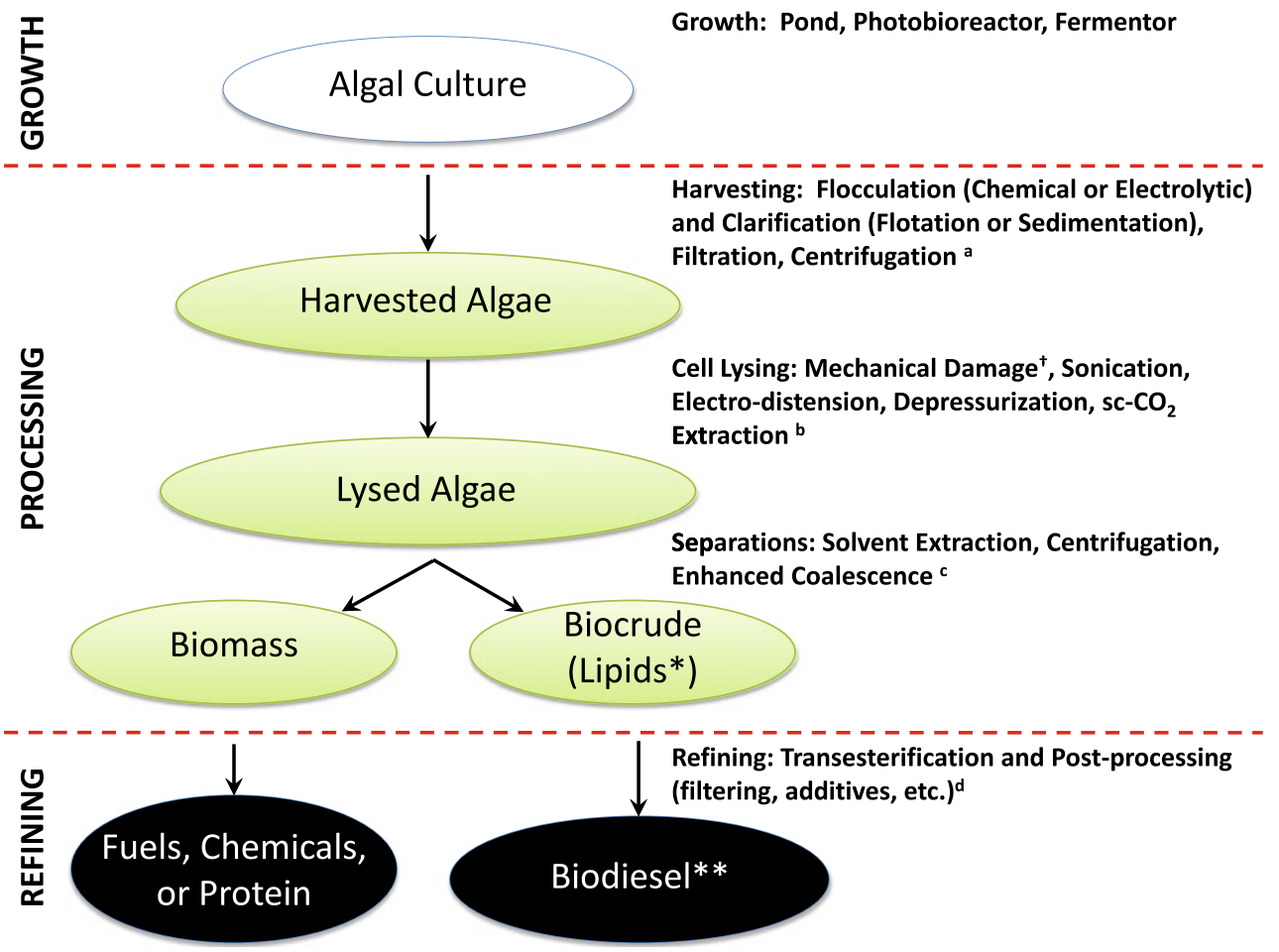




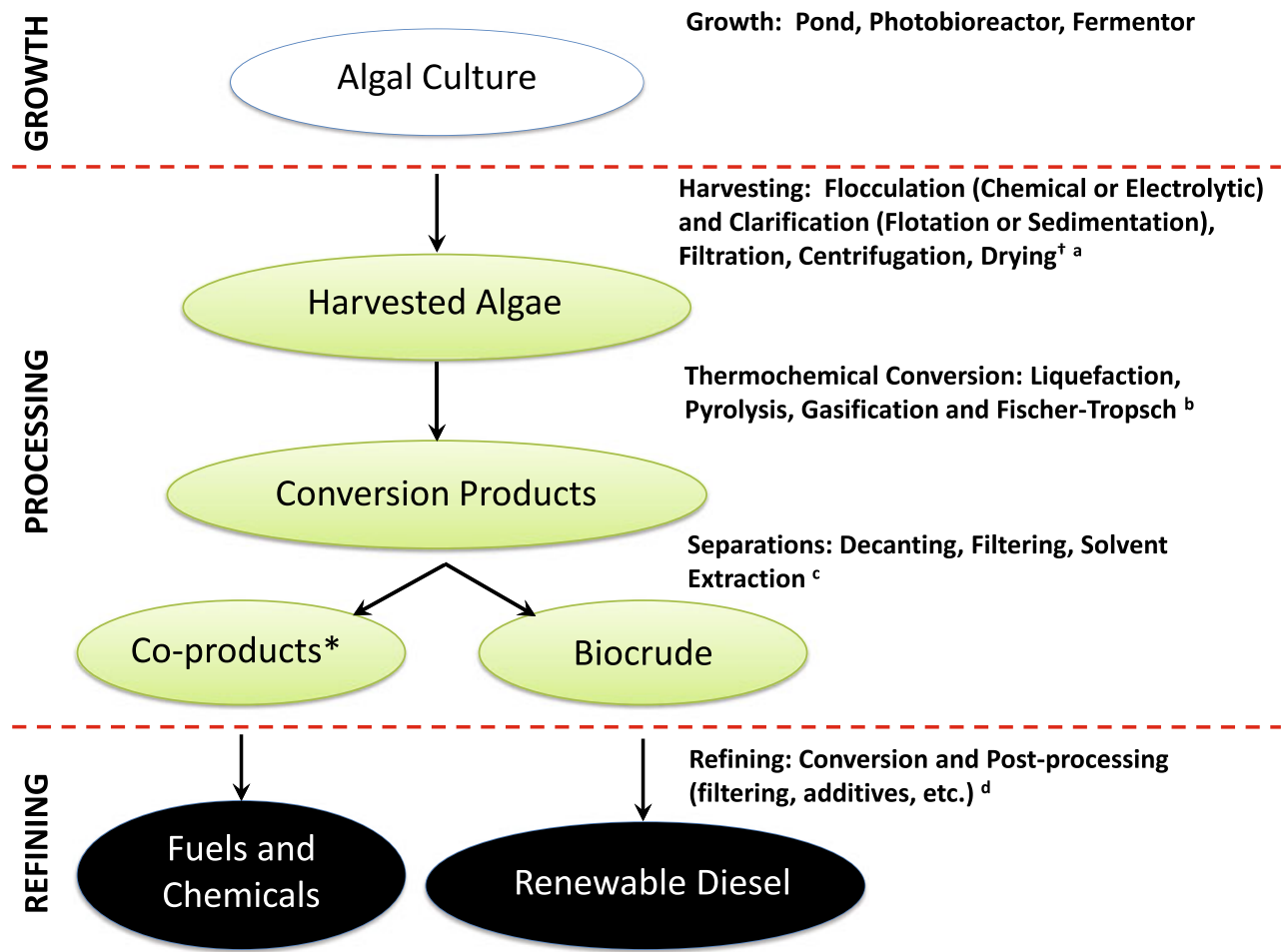

Fig. 3 The production of renewable diesel by thermochemical conversion of algal biomass contains several production steps, and many thermochemical conversion processes exist. $\dagger$ Harvesting may or may not include complete drying, depending on the thermochemical

Each pathway is segmented into the three production phases listed in Fig. 1 (i.e., growth, processing, and refining). All of the production steps within each phase impact the efficiency, cost, and energy requirement for that phase. In this regard, the pathways shown here can be further expanded to include conversion process. *Co-products composition depends on the conversion process used. $a$ [20, 23-28], $b[11,33,37,56-67], c[11$, $33,56,59,64], d[27,33,36-40]$

additional sub-level production steps and can be tailored to accommodate other production methods. The degree to which a pathway is segmented into discrete steps and the categories that are used to group the steps are somewhat arbitrary and left to the discretion of the practitioner.
Fig. 4 The production of renewable diesel from algal oil that is secreted into the growth medium is a relatively new approach. *In this process, the algal culture often consists of genetically modified organisms [68-76]

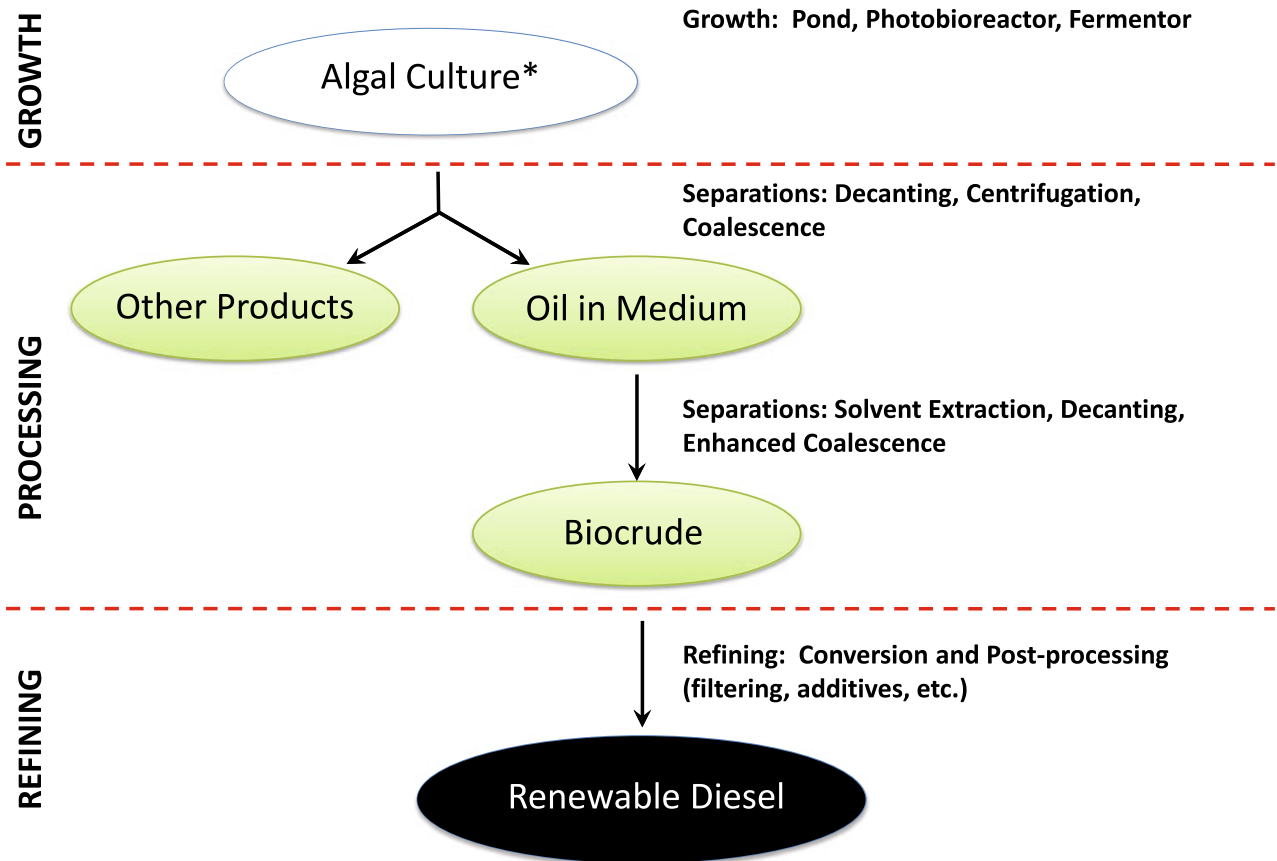


Transesterification of Extracted Lipids

Figure 2 is a flow chart showing the main processes that are required to produce biodiesel, a form of renewable diesel, from extracted algal lipids, which is the most commonly investigated of the three pathways presented here. After algae are grown in an open pond, photobioreactor, or fermentor (i.e., heterotrophic growth), the algae are harvested from the growth medium. After harvesting, the lipids are extracted from the algal cells. This extraction generally consists of a lysing process to rupture the cells followed by a separation of the lipids from the other biomass. Alternatively, direct solvent extraction can be conducted to extract lipids, although it may be infeasible on the industrial scale. Additional separations may be required to obtain only the lipids that are specifically useful for biodiesel production. These lipids are referred to as useful lipids and are discussed in more detail below. Once the useful lipids have been separated, they are converted to fatty acid methyl esters (FAME) via transesterification. Biodiesel is a term that we use to refer to a composition consisting mainly of fatty acid methyl esters that complies with standard fuel specifications. There is also potential for producing valuable coproducts, such as glycerol, protein, or biomass. The biomass co-product could be converted to fuels (via anaerobic digestion or gasification) or used to produce electricity (via direct combustion). A more detailed discussion of the intermediate products in this production pathway is provided in Appendix 2.

\section{Thermochemical Biomass Conversion}

Thermochemical conversion of algal biomass is another processing method that can be used to produce renewable diesel, and the associated production pathway is shown in Fig. 3. After the algae are grown, they are harvested and, in some cases, dried (depending on the thermochemical conversion process applied). Biomass is the substrate for thermochemical processes, and therefore, the entire algal cell undergoes conversion. The most common thermochemical processes are liquefaction, pyrolysis, and gasification with subsequent Fischer-Tropsch conversion.

Each of these processes converts algal biomass to products that can potentially be upgraded to renewable diesel. Liquefaction converts high molecular weight organic compounds to low molecular weight oils at temperatures around $250-350^{\circ} \mathrm{C}$, high pressure $(0.5-20 \mathrm{MPa})$, and often with the aid of a catalyst $[11,33,37,56-58,77,78]$. Pyrolysis is defined as the conversion of high molecular weight organic compounds to oil under high temperature $\left(\sim 480-700^{\circ} \mathrm{C}\right)$, in the absence of oxygen, and under operating pressures of $\sim 0.1-0.5 \mathrm{MPa}[37,59,77-79]$.
Algae may also be converted to syngas by gasification, which could then be converted to biocrude by the FischerTropsch process $[9,60-63,80-84]$. The co-products of each thermochemical conversion process vary and can include gases, aqueous liquids, and solid char.

Following thermochemical conversion, the oils (i.e., biocrude) are separated (usually by solvent extraction with chloroform or dichloromethane) $[11,33,56,59,64]$ and may be refined into renewable diesel. There is also potential for the production of valuable co-products with thermochemical algal biomass conversion. For instance, the gaseous product contains methane, and the solid char residue could be used as a combustion fuel or soil additive.

\section{Conversion of Secreted Algal Oils}

Another method that has been explored for renewable diesel production is the collection and conversion of secreted algal oils (sometimes called milking). The aim of this method is to use genetically modified organisms that secrete oils into the growth medium. The production of renewable diesel from secreted algal oils is the least mature of the three production pathways presented here. Much of the work in this area to date is proprietary. As a result, the feasibility of this production pathway is unclear. The increased cost of engineering a suitable organism and maintaining a monoculture may be offset by a reduction in processing cost required to produce renewable diesel, as compared to the lipid extraction and thermochemical conversion production pathways shown above. The most general steps required for producing renewable diesel from secreted algal lipids are shown in Fig. 4.

The first processing step required in this production pathway is the separation of secreted oil from the growth medium. The term "oils" is used here rather than "lipids" because the exact composition of the secreted products is not yet known. As a result, secondary separations may be required to recover oils that are specifically useful for refining into renewable diesel

\section{Framework Principles}

In this section, a proposed framework is presented that uses the nomenclature developed in this work (specifically, for transesterification of algal lipids as detailed in Appendix 2). The framework is based on three principles: using strong reporting metrics, using symbolic notation to include unknown values, and ensuring that results are presented consistently. Each of these principles is discussed in detail below. 


\section{Strong Metrics}

First, results should be reported with the strongest metric possible. The strength of a metric refers to the amount of information relevant to renewable diesel production that it contains. For instance, the metric "triacylglycerol per dry weight" is stronger than "lipid per dry weight" because it includes additional information about the composition of the lipids. Similarly, the renewable diesel productivity, $P_{\mathrm{RD}}$, is a stronger metric than triacylglycerol productivity, $P_{\mathrm{TAG}}$, and this concept is illustrated in Fig. 5.

The scope of a particular study determines the amount of information that is obtained and the associated reporting metric. Figure 5 illustrates how metric strength increases as the breadth of information conferred by the metric increases. It does not include all relevant metrics for renewable diesel production from algae. For example, a primary study may focus on determining the amount of $\mathrm{CO}_{2}$ required for large-scale algal cultivation, a subset of the "Materials Consumed for Growth" metric.

Figure 6 lists the productivity, cost, and energy requirements associated with each intermediate product in the production pathway (specifically, transesterification of algal lipids) in order of metric strength.
Use of Symbolic Notation

The second principle for the proposed characterization framework is that results from studies with limited scope can be reported with strong metrics by including unknown information in symbolic notation. There are two main advantages of presenting information in this manner: (1) it ensures that results are not taken out of context, thus helping to avoid incomplete estimates for the potential of renewable diesel from algae, and (2) it explicitly identifies the areas where additional data are needed to complete the production pathway analysis. In addition, using symbolic notation enables results to be incorporated into systems-level analyses more directly. The nomenclature used in this section is described in detail in Appendix 2.

To demonstrate reporting results with unknowns in symbolic notation in an example, the triacylglycerol productivity, $P_{\mathrm{TAG}}$, of a culture can be expressed as

$P_{\mathrm{TAG}}=\frac{M_{\mathrm{TAG}}}{V_{\mathrm{G}} \cdot t}=P_{\mathrm{GM}} \cdot \varphi_{\text {harv }} \cdot \varphi_{\text {cellys }} \cdot \varphi_{\text {sep }} \quad\left[\frac{\mathrm{g}}{\mathrm{L}_{\mathrm{G}} \cdot \mathrm{day}}\right]$

where $P_{\mathrm{GM}}$ is the grown mass productivity and the efficiencies are defined in Appendix 2. Note that triacyl-

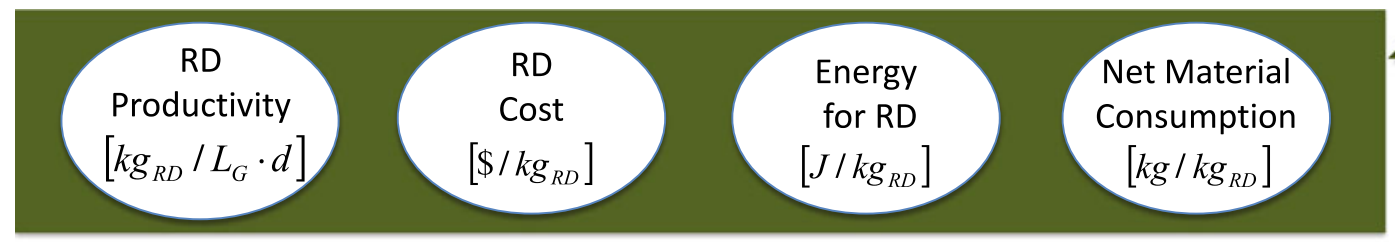

Post-Processing Inputs and Efficiencies

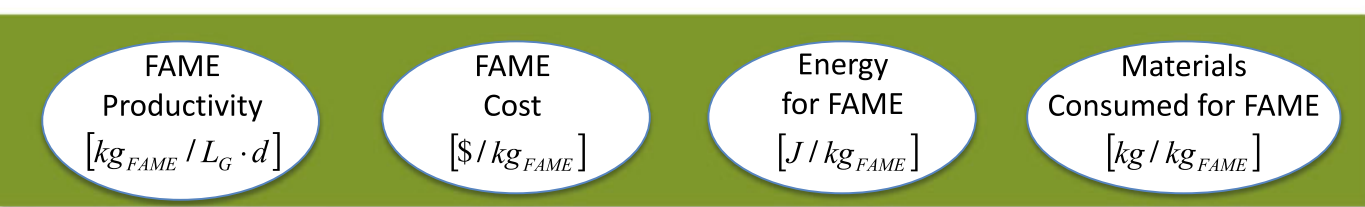

Transesterification Inputs and Efficiencies
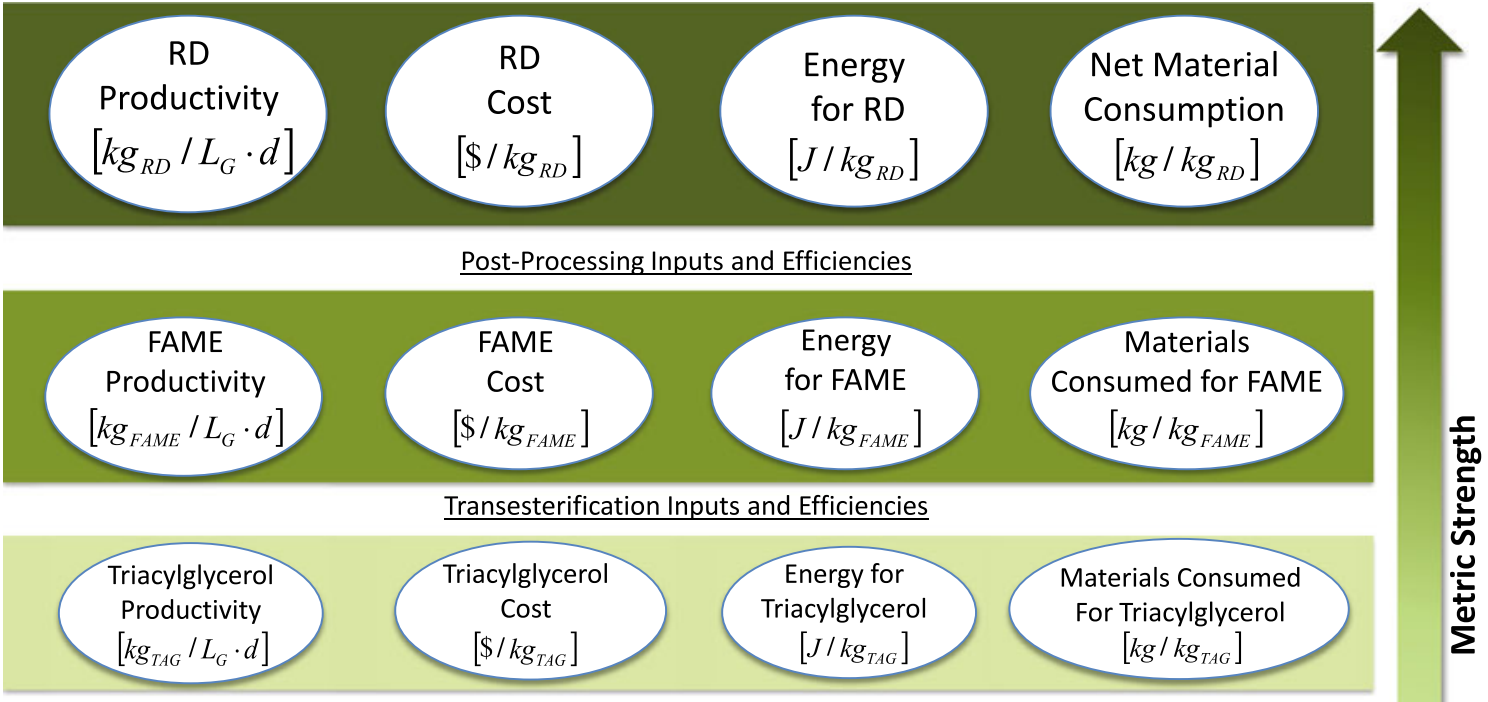

Triacylglycerol Separation Inputs and Efficiencies

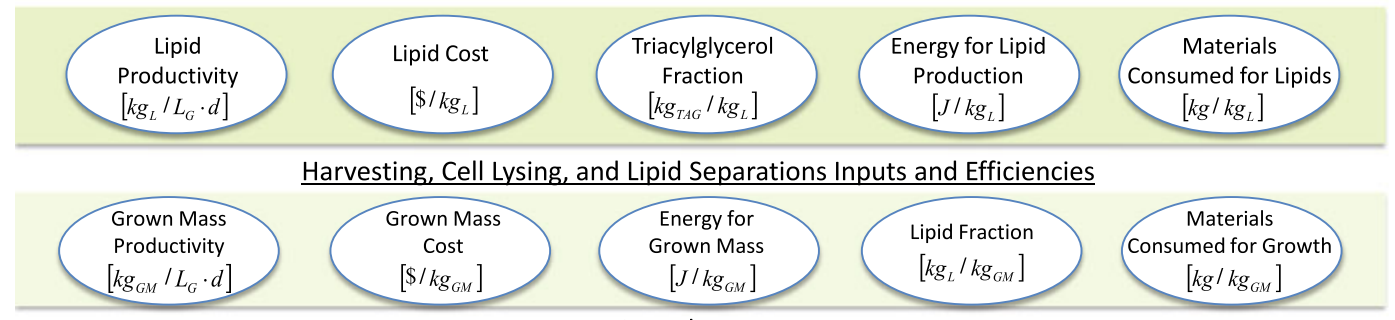

Growth Inputs

Fig. 5 Metric strength increases as the amount of information that the metric contains increases. It is important that results are consistent in algal species and growth conditions and include all relevant inputs and processing steps. It is assumed for this figure that renewable diesel (specifically, biodiesel) can only be made from triacylglycerol, rather than all lipids 
a

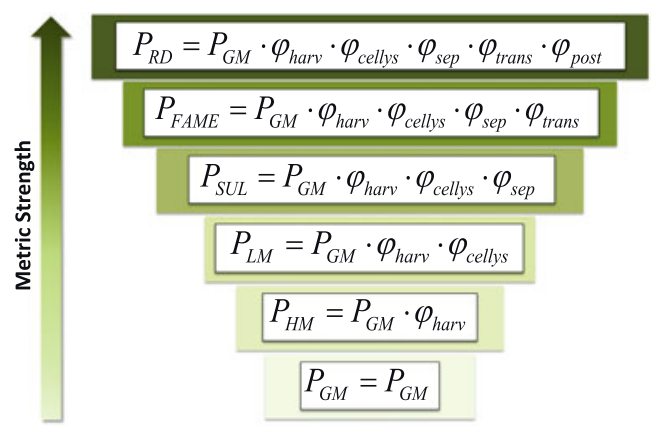

b

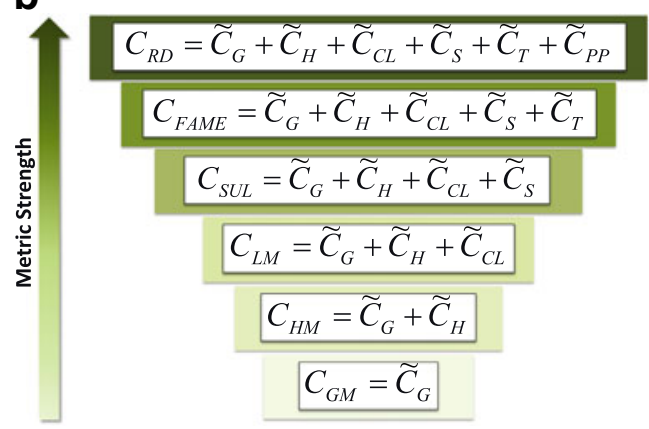

C

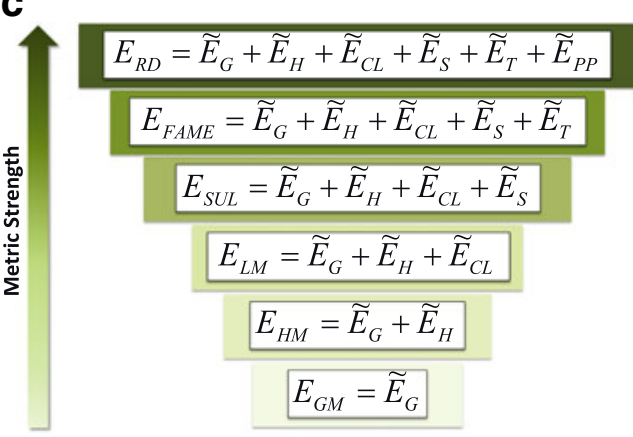

Fig. 6 The productivity, cost, and energy requirements associated with producing each intermediate product can be written as an inverted pyramid, with the strongest metrics representing the entire production pathway. The subscripts on the left-hand side of the equations are renewable diesel (RD), fatty acid methyl esters (FAME), separated useful lipids (SUL), lysed mass (LM), harvested mass (HM), and grown mass (GM). The overall units for these equations are grams per liter of growth volume per day, dollars per liter of renewable diesel, and joules per liter of renewable diesel for the productivity, cost, and energy equations, respectively (recall that the tilde denotes a processing step cost or energy requirement and that this nomenclature is specific to transesterification of algal lipids)

glycerol is a subset of useful lipids, and therefore, the separation efficiency (cf. Eq. 33), $\varphi_{\text {sep }}$, can be evaluated as

$$
\varphi_{\mathrm{sep}}=\mathrm{LF} \cdot \varphi_{\mathrm{sep}_{\mathrm{L}}} \cdot \mathrm{TAGF} \cdot \varphi_{\mathrm{sep}_{\mathrm{TAG}}}[-]
$$

where TAGF is the triacylglycerol fraction, which is the fraction of lipids that are triacylglycerol (g triacylglycerol/g lipid), and $\varphi_{\text {sep }_{\mathrm{TAG}}}$ is the efficiency with which the triacylglycerol can be separated from the other lipids. These terms have been substituted for the useful lipid fraction, ULF, and useful lipid separations efficiency, $\varphi_{\text {sep }_{\text {ur }}}$, of Eq. 33. In a situation where a researcher may not have all of the above information, the results could be reported in symbolic notation. For instance, in a study by Richmond et al., Nannochloropsis salina was produced at a rate of $24.5 \mathrm{~g} /\left(\mathrm{m}^{2}\right.$-day $)$ with a lipid fraction of about $16 \%$ in a pond with $0.12 \mathrm{~m}$ depth (cf. Sheehan et al. 1998, p. 191). This information translates to a triacylglycerol productivity that can be reported as

$$
\begin{array}{ll}
P_{\mathrm{TAG}}=\frac{24.5}{0.12 \cdot 1,000} \cdot \varphi_{\text {harv }} \cdot \varphi_{\text {cellys }} \cdot 0.16 \cdot \varphi_{\mathrm{sep}_{\mathrm{L}}} \cdot \mathrm{TAGF} \cdot \varphi_{\mathrm{sep}_{\mathrm{TAG}}} & {\left[\frac{\mathrm{g}}{\overline{\mathrm{L}_{\mathrm{G}}} \cdot \mathrm{day}}\right]} \\
P_{\mathrm{TAG}}=0.033 \cdot \varphi_{\text {harv }} \cdot \varphi_{\text {cellys }} \cdot \varphi_{\mathrm{sep}_{\mathrm{L}}} \cdot \mathrm{TAGF} \cdot \varphi_{\mathrm{sep}_{\mathrm{TAG}}} & {\left[\frac{\mathrm{g}}{\overline{\mathrm{L}_{\mathrm{G}}} \cdot \mathrm{day}}\right]}
\end{array}
$$

Leaving the triacylglycerol fraction, TAGF, in symbolic form helps to avoid using the terms "lipid" and "triacylglycerol" synonymously. Furthermore, leaving the processing efficiencies in symbolic notation clarifies that the triacylglycerol productivity, $P_{\mathrm{TAG}}$, is dependent on the processing methods.

To further illustrate the use of symbolic notation, renewable diesel productivity, $P_{\mathrm{RD}}$, can be used to present the results for heterotrophic growth of Chlorella protothecoides presented by $\mathrm{Li}$ et al. [18]. The 8,000-L growth volume used in that study produced an algal density of $14.2 \mathrm{~g} / \mathrm{L}$ with a lipid fraction, $\mathrm{LF}$, of $44.3 \%$, and $98 \%$ of the lipids were converted to FAME via transesterification. The cultivation period was 8.33 days, yielding a grown mass productivity, $P_{\mathrm{GM}}$, of $1.70 \mathrm{~g} /(\mathrm{L}$-day). However, the transesterification efficiency was not reported on a mass basis, the harvesting efficiency was not reported, and postprocessing was not conducted. Therefore, these values can be best represented in symbolic notation, and the renewable diesel productivity in the study by $\mathrm{Li}$ et al. can be reported as

$$
\begin{aligned}
P_{\mathrm{RD}} & =P_{\mathrm{GM}} \cdot \varphi_{\text {harv }} \cdot \varphi_{\text {cellys }} \cdot \varphi_{\text {sep }} \cdot \varphi_{\text {trans }} \cdot \varphi_{\text {post }}\left[\frac{\mathrm{g}}{\mathrm{L}_{\mathrm{G}} \cdot \text { day }}\right] \\
P_{\mathrm{RD}} & =P_{\mathrm{GM}} \cdot \varphi_{\text {harv }} \cdot \varphi_{\text {cellys }} \cdot \mathrm{LF} \cdot \varphi_{\mathrm{sep}_{\mathrm{L}}} \cdot \mathrm{ULF} \cdot \varphi_{\text {sep }_{\mathrm{UL}}} \cdot \varphi_{\text {trans }} \cdot \varphi_{\text {post }}\left[\frac{\mathrm{g}}{\mathrm{L}_{\mathrm{G}} \cdot \text { day }}\right] \\
& =1.70 \cdot \varphi_{\text {harv }} \cdot 1 \cdot 0.443 \cdot 1 \cdot 1 \cdot 1 \cdot \varphi_{\text {trans }} \cdot \varphi_{\text {post }}\left[\frac{\mathrm{g}}{\mathrm{L}_{\mathrm{G}} \cdot \text { day }}\right]
\end{aligned}
$$

or

$$
P_{\mathrm{RD}}=0.75 \cdot \varphi_{\text {harv }} \cdot \varphi_{\text {trans }} \cdot \varphi_{\text {post }} \quad\left[\frac{\mathrm{g}}{\mathrm{L}_{\mathrm{G}} \cdot \mathrm{day}}\right]
$$

In Eq. 19, the cell lysing efficiency, $\varphi_{\text {cellys, }}$ lipid separation efficiency, $\varphi_{\text {sep }_{\mathrm{L}}}$, and the useful lipid separation efficiency, $\varphi_{\text {sep }_{U L}}$, were assumed to be unity because the lipid fraction was determined from the amount of lipid separated, thus already containing the lysing and lipid separations efficiency, and all extracted lipids were used for the production of FAME. For this calculation, it is also 
assumed that the lipid fraction remains constant throughout harvesting and lysing. The validity of that assumption is not known.

Similarly, symbolic notation can be used to report financial and energy costs. For example, Schenk et al. [16] cited the cost of producing algal oil (between $\$ 126$ and $\$ 209$ US(2008)/bbl or between \$0.79 and \$1.31 US(2008)/ L) based on Seambiotic Inc. biomass growth and harvesting costs of $\$ 0.34 / \mathrm{kg}$ of dry algae (i.e., harvested dry mass). The algae in that study were reported to have a lipid fraction, LF, of $24 \%$. Schenk et al. assumed no additional processing cost [16]. We suggest that the cost of producing renewable diesel from this biomass is aptly characterized by Eq. 20, which is

$$
C_{\mathrm{RD}}=c_{\mathrm{RD}} \cdot \rho_{\mathrm{RD}}=\widetilde{C}_{\mathrm{G}}+\widetilde{C}_{\mathrm{H}}+\widetilde{C}_{\mathrm{CL}}+\widetilde{C}_{\mathrm{S}}+\widetilde{C}_{\mathrm{T}}+\widetilde{C}_{\mathrm{PP}} \quad\left[\frac{\$}{\mathrm{~L}_{\mathrm{RD}}}\right]
$$

To evaluate Eq. 20, the growth and harvesting processing costs can be combined to obtain an expression for the cost of harvested (algal) mass. Combining Eqs. 5 and 41, the processing costs of growing and harvesting algal biomass in dollars per liter of renewable diesel, $\widetilde{C}_{\mathrm{G}}+\widetilde{C}_{\mathrm{H}}$, can be expanded as

$$
\begin{aligned}
\widetilde{C}_{\mathrm{G}}+\widetilde{C}_{\mathrm{H}}= & C_{\mathrm{HM}}=\widetilde{c}_{\mathrm{G}} \cdot \mathrm{GMCF} \cdot \rho_{\mathrm{RD}}+\widetilde{c}_{\mathrm{H}} \cdot \mathrm{HMCF} \\
& \cdot \rho_{\mathrm{RD}}\left[\frac{\$}{\mathrm{~L}_{\mathrm{RD}}}\right]
\end{aligned}
$$

where $C_{\mathrm{HM}}$ represents the cost of harvested (algal) mass (i.e., grown and harvested) per liter of renewable diesel. Equation 21 reduces to

$$
\widetilde{C}_{\mathrm{G}}+\widetilde{C}_{\mathrm{H}}=\left(\widetilde{c}_{\mathrm{G}} \cdot \frac{1}{\varphi_{\text {har }}}+\widetilde{c}_{\mathrm{H}}\right) \cdot \mathrm{HMCF} \cdot \rho_{\mathrm{RD}} \quad\left[\frac{\mathrm{s}}{\mathrm{L}_{\mathrm{RD}}}\right]
$$

and the cost of harvested (algal) mass per kilogram, $c_{\mathrm{HM}}$, is

$c_{\mathrm{HM}}=\left(\widetilde{c}_{\mathrm{G}} \cdot \frac{1}{\varphi_{\text {harv }}}+\widetilde{c}_{\mathrm{H}}\right) \quad\left[\frac{\$}{\mathrm{~kg}_{\mathrm{HM}}}\right]$

Equation 23 is useful to illustrate the distinction between $\widetilde{c}_{\mathrm{H}}$, which is the cost of the harvesting process per kilogram of harvested mass, and $c_{\mathrm{HM}}$, which is the total cost of producing harvested mass (which includes growth costs). Equation 21 can therefore be written more concisely as

$$
\widetilde{C}_{\mathrm{G}}+\widetilde{C}_{\mathrm{H}}=C_{\mathrm{HM}}=c_{\mathrm{HM}} \cdot \mathrm{HMCF} \cdot \rho_{\mathrm{RD}} \quad\left[\frac{\mathrm{s}}{\mathrm{L}_{\mathrm{RD}}}\right]
$$

Equation 24 can be populated with the data reported by Schenk et al. $\left(c_{\mathrm{HM}}=\$ 0.34 / \mathrm{kg}\right.$ and $\left.\rho_{\mathrm{RD}}=0.92 \mathrm{~kg} / \mathrm{L}\right)$, and the cost of producing harvested (algal) dry mass per liter of renewable diesel can be calculated as

$$
\widetilde{C}_{\mathrm{G}}+\widetilde{C}_{\mathrm{H}}=C_{\mathrm{HM}}=0.34 \cdot \mathrm{HMCF} \cdot 0.92 \quad\left[\frac{\$}{\mathrm{LD}_{\mathrm{RD}}}\right]
$$

Evaluating the lipid fraction, LF, as $24 \%$ in HMCF and reducing yields

$$
\widetilde{C}_{\mathrm{G}}+\widetilde{C}_{\mathrm{H}}=1.31 \cdot \frac{1}{\varphi_{\text {cellys }}} \cdot \frac{1}{\varphi_{\text {sep }}} \cdot \frac{1}{\varphi_{\text {trans }}} \cdot \frac{1}{\varphi_{\text {post }}} \quad\left[\frac{\$}{\mathrm{~L}_{\mathrm{RD}}}\right]
$$

Then, using the cost of the transesterification process per liter of FAME produced (i.e., $\widetilde{c}_{\mathrm{T}} \cdot \rho_{\mathrm{RD}}$ ) to be about $\$ 0.13$ US(2008)/L [22], the total cost of producing algae-derived renewable diesel (combining Eq. 26 with Eq. 20) can be expressed as

$$
\begin{aligned}
C_{\mathrm{RD}}= & 1.31 \cdot \frac{1}{\varphi_{\text {cellys }}} \cdot \frac{1}{\varphi_{\text {sep }}} \cdot \frac{1}{\varphi_{\text {trans }}} \cdot \frac{1}{\varphi_{\text {post }}}+\widetilde{C}_{\mathrm{CL}}+\widetilde{C}_{\mathrm{S}} \\
& +0.13 \cdot \frac{1}{\varphi_{\text {post }}}+\widetilde{C}_{\mathrm{PP}}\left[\frac{\$}{\mathrm{~L}_{\mathrm{RD}}}\right]
\end{aligned}
$$

Using symbolic notation can also improve the consistency of reporting results associated with the net energy ratio for producing algal renewable diesel. For example, Benemann and Oswald present an energy analysis for fuel inputs required for growing and harvesting algae and report the energy requirement for producing harvested algal biomass, $e_{\mathrm{HM}}$, of between 0.924 and $1.202 \mathrm{~kJ} / \mathrm{kg}$ (note, $\widetilde{e}_{\mathrm{GM}} \cdot \frac{1}{\varphi_{\text {har }}}+\widetilde{e}_{\mathrm{H}}=e_{\mathrm{HM}}$, where $\varphi_{\text {harv }}$ is assumed to be 1 , cf. Appendix 2) [22]. Therefore, as described in detail in Appendix 2, using $e_{\mathrm{HM}}=1.202 \mathrm{~kJ} / \mathrm{kg}$, the energy required for growing and harvesting per liter of renewable diesel, $\widetilde{E}_{\mathrm{G}}+\widetilde{E}_{\mathrm{H}}$, can be approximated as

$$
\widetilde{E}_{\mathrm{G}}+\widetilde{E}_{\mathrm{H}}=1.202 \cdot \mathrm{HMCF} \cdot \rho_{\mathrm{RD}} \quad\left[\frac{\mathrm{kJ}}{\mathrm{L}_{\mathrm{RD}}}\right]
$$

Using this value, a LHV of renewable diesel to be $41 \mathrm{MJ} / \mathrm{kg}$ [19], and the density of renewable diesel, $\rho_{\mathrm{RD}}$, as $0.92 \mathrm{~kg} / \mathrm{L}$ in the energy return on energy investment (Eq. 15) yields

$$
\mathrm{EROI}_{\mathrm{RD}}=\frac{41,000 \cdot 0.92+\mathrm{EC}_{\mathrm{CP}}}{1.202 \cdot \mathrm{HMCF} \cdot 0.92+\widetilde{E}_{\mathrm{CL}}+\widetilde{E}_{\mathrm{S}}+\widetilde{E}_{\mathrm{T}}+\widetilde{E}_{\mathrm{PP}}} \quad[-]
$$

Combining Eqs. 28 and 53 produces the denominator of Eq. 29. One can see that the EROI is dependent upon the energy requirements of all processing steps, and additional data are needed to accurately assess these terms. The energy ratio is also dependent on the allocation of indirect energy requirements. For example, Clarens et al. [51] include the energy embedded in nutrients (including $\mathrm{CO}_{2}$ ) in their life cycle analysis, which yields a growing and harvesting energy requirement of $22,710 \mathrm{~kJ} / \mathrm{kg}$ of harvested algae. This result is four orders of magnitude greater than the estimate provided by Benemann and Oswald that is used in Eq. 29. Lardon et al. and Beal et al. have also conducted a net energy balance 
associated with renewable diesel and have also used unique system boundaries $[85,113]$.

\section{Reporting Consistency}

The third principle for the characterization framework is that results associated with renewable diesel production from algae should be reported consistently. Consistent refers to presenting results that are specific (to algal species, growth conditions, and product composition) and inclusive (of all inputs and processing steps) and that consider the energy, materials, and cost associated with all relevant production pathway steps.

\section{Specific Results}

Due to the scope of a particular study, some reported results are not explicit with respect to algal species, growth conditions, or product composition [11, 17, 38, 59, 86-91]. As a result of the variety among algal species, even within a single genus, it is important that the characteristics of one alga are not mixed with those of another for analytical calculations. The energy, cost, and materials required for production typically vary with species. This lack of specificity in the results of many studies limits their utility.

It is also important to be specific when citing results that are dependent upon growth conditions. Combining results for the maximum lipid fraction ( $\mathrm{g}$ lipid/g of algal mass) of a particular alga (often obtained under nutrient deficient conditions) with the maximum growth rate of that alga (generally obtained under nutrient replete conditions) introduces an inconsistency in the resulting lipid productivity. This practice is misleading because growth rate and lipid production are generally inversely related [1].

There are several different metrics that are often used to evaluate algal biofuel potential including lipid content, neutral lipid content, triacylglycerol content, etc. If these terms are improperly used as synonyms, comparisons among various results are not direct comparisons. For instance, the terms "oil" or "algae oil" are frequently used for reporting results without defining the chemical composition of these substances. These terms have been used to refer to algal lipids, biodiesel, and even ethanol. The lack of specificity regarding these metrics needlessly limits the value of the published results.

Finally, neglecting to distinguish among types of biofuels can also introduce ambiguity in analyses. For example, ethanol contains about $70 \%$ of the energy content per volume of biodiesel $[19,92]$.

\section{Inclusive Results}

Many studies specifically addressing the production of renewable diesel from algae could be more widely useful if they included information encompassing more of the produc- tion pathway $[16,17,19,64,91,93-96]$. While the scope of a study determines the breadth of information available, it is useful to rigorously place the work in the context of the entire production pathway. As suggested by Griffiths and Harrison [41], this benefit is particularly true for studies that include information regarding the products of interest in algal cultures for biodiesel production (i.e., lipids or triacylglycerol). For example, if a researcher evaluates the impact of different nutrients on lipid production, the results for that study are most useful if they provide more information than simply the lipid fraction, LF, of the cultures.

It is also important to include information about all relevant parts of the production pathway due to the variability of algal cultures. Downstream processing studies have been conducted to evaluate the efficiency of processing algae or "algae oil," without including relevant information about the algal species, lipid content, or oil composition [93, 94]. Since growth rate, lipid content, and lipid composition can vary widely depending on species or growth conditions [1, 21, 41, 97-105], the processing efficiencies determined for one alga or one composition of "algae oil" may differ from those associated with different algae or oil compositions. The resources required for production may also vary depending on species [58]. Including the algal species and/or the composition of the tested algal oil would reduce these inconsistencies.

Also, there is a significant discrepancy among costs on a lab scale, pilot scale, and commercial scale and among results obtained for short-term versus long-term experiments. Correlating data among these scales and time frames is challenging, and the scalability of algal production for biofuels is an ongoing area of research. To advance this research area, which is critical for producing accurate estimates of the potential of algae for renewable diesel, it is valuable to be as specific about the growth volume and time period as possible because the cultivation scale can impact growth characteristics $[1,16]$.

Finally, several systems-level analyses have calculated estimates for the total land area (for open ponds) or growth volume (for bioreactors) required to cultivate enough microalgae needed to produce a specified amount of diesel fuel substitute (such as to satisfy the US diesel consumption) $[16,17,86,87,106]$. Other studies present estimates for the total financial cost of producing "algae oil" in terms such as dollars per barrel [1, 16, 17, 20, 22, 88, 95, 106]. However, some of these analyses, including some analyses listed in Table 1, omit important pieces of the production pathway, leading to inconsistent results.

\section{Energy, Materials, and Cost Balances}

The third way to improve reporting consistency is by considering the energy, materials, and cost requirements for each production process. These requirements are relevant for specific studies conducted by primary researchers (e.g., 
energy required to grow a culture) and especially for systems-level researchers who characterize the potential for algae-based biofuel. In fact, the two are directly linked. Without energy, materials, and cost information associated with primary studies of individual processes, it is impossible to compile the energy balance of the entire production pathway.

There are numerous primary studies on algal growth, lipid composition, and processing methods $[1,21,41-43$, 64, 98, 100-102, 104, 107-110]. The impact of many primary studies could potentially be increased with the inclusion of energy, cost, and material requirements. For instance, if a study on the lipid fraction of different algal species includes the amount of energy, materials, and cost required to produce the lipid, its results could be more broadly interpreted. Information that is not relevant or not known can be presented in symbolic notation, as suggested above, to enable the use of strong reporting metrics.

It is also important that top-level analyses of renewable diesel produced from algae address the energy, materials, and cost requirements for renewable diesel production consistently. Significant inconsistencies can arise when the requirements for entire production steps are omitted or oversimplified. Several systems-level analyses have been published for renewable diesel from algae (primarily biodiesel), each with a different amount of information regarding energy, cost, and material requirements $[1,16,17,20,22,37,58,88,95,106$, 111]. These systems-level cost analyses provide good outlines for conducting cost estimates, but sometimes lack specificity to algal species or growth conditions, and may omit some required processing steps. Processing efficiencies and resource requirements may depend on the algal species and composition [16, 20, 23, 58, 93].

\section{Conclusion}

For the field of algae-derived renewable diesel to progress, the community of researchers needs to provide accurate answers to the three questions: (1) how much renewable diesel can be produced, (2) how much will this renewable diesel cost, and (3) what are the energy requirements for production? We have proposed a framework and associated nomenclature system for characterizing the potential of algae for renewable diesel that outlines a method for presenting consistent, widely interpretable results. This framework consists of three principles: using strong metrics, using symbolic representation for unknown information, and presenting results that are consistent and include all relevant information. Widespread use of common nomenclature and a consistent reporting framework by primary researchers would allow systems-level analysts to integrate the results of primary research into estimates for the potential of algae for renewable diesel. In turn, widespread use of a framework by systems-level analysts would lead to improved estimates, which are valuable for researchers and policy makers. Accurate and informative estimates of the potential of renewable diesel will help researchers focus their efforts on the most pressing problems and help policy makers make appropriate decisions about funding and resource allocation related to algal biofuel development.

Acknowledgments We would like to thank the Center for Electromechanics at the University of Texas at Austin and OpenAlgae LLC for their collaboration and partial funding of this research. Specifically, we would like to acknowledge R. Connelly, M. Fountain, L. Katz, K. Kinney, R. Pearsall, M. Poenie, F. Seibert, and M. Werst for developing an initial approach to algal biodiesel production, which has been a useful model for developing the proposed reporting framework. We would also like to thank R. Weber (Sunrise Ridge Algae, Inc.), T. Campione (Solazyme), and T. Edgar (University of Texas at Austin) for their comments. Finally, we would like to acknowledge D. Dreyer and P. Palmer for their assistance in preparing the manuscript.

Open Access This article is distributed under the terms of the Creative Commons Attribution Noncommercial License which permits any noncommercial use, distribution, and reproduction in any medium, provided the original author(s) and source are credited.

\section{Appendix 1}

Glossary of Symbols and Associated Units

\section{Productivity}

$\begin{array}{ll}P_{\mathrm{GM}} & \text { Grown mass productivity }\left[\frac{\mathrm{g}}{\mathrm{L}_{\mathrm{G}} \cdot \text { day }}\right] \\ P_{\mathrm{HM}} & \text { Harvested mass productivity }\left[\frac{\mathrm{g}}{\mathrm{L}_{\mathrm{G}} \cdot \text { day }}\right] \\ P_{\mathrm{LM}} & \text { Lysed mass productivity }\left[\frac{\mathrm{g} \cdot}{\mathrm{L}_{\mathrm{G}} \cdot \text { day }}\right] \\ P_{\mathrm{SL}} & \text { Total separated lipids productivity }\left[\frac{\mathrm{g}}{\mathrm{L}_{\mathrm{G}} \cdot \mathrm{day}}\right] \\ P_{\mathrm{SUL}} & \text { Separated useful lipids productivity }\left[\frac{\mathrm{g}}{\mathrm{L}_{\mathrm{G}} \cdot \text { day }}\right] \\ P_{\mathrm{TAG}} & \text { Triacylglycerol productivity }\left[\frac{\mathrm{g}}{\mathrm{L}_{\mathrm{G}} \cdot \text { day }}\right] \\ P_{\mathrm{FAME}} & \text { Fatty acid methyl esters productivity }\left[\frac{\mathrm{g}}{\mathrm{L}_{\mathrm{G}} \cdot \text { day }}\right] \\ P_{\mathrm{BD}} & \text { Biodiesel productivity }\left[\frac{\mathrm{g}}{\mathrm{L}_{\mathrm{G}} \cdot \text { day }}\right] \\ P_{\mathrm{RD}} & \text { Renewable diesel productivity }\left[\frac{\mathrm{g}}{\mathrm{L}_{\mathrm{G}} \cdot \text { day }}\right] \\ M_{\mathrm{RD}} & \text { Renewable diesel mass }[\mathrm{g}] \\ M_{\mathrm{BC}} & \text { Biocrude mass [g] } \\ M_{\mathrm{GM}} & \text { Grown algal mass [g] } \\ M_{\mathrm{SUL}} & \text { Separated useful lipid mass }[\mathrm{g}] \\ M_{\mathrm{LM}} & \text { Lysed algal mass [g] } \\ M_{\mathrm{TAG}} & \text { Triacylglycerol mass [g] } \\ V_{\mathrm{G}} & \text { Volume of growth medium }[\mathrm{L}] \\ t_{\mathrm{c}} & \text { Cultivation time [day }] \\ \varphi_{\text {proc }} & \text { Processing efficiency [-] } \\ \varphi_{\text {ref }} & \text { Refining efficiency [-] } \\ \varphi_{\text {harv }} & \text { Harvesting efficiency [-] } \\ \varphi_{\text {cellys }} & \text { Cell lysing efficiency [-] } \\ \varphi_{\text {sep }} & \text { Overall separations efficiency }[-] \\ \varphi_{\text {sep }} & \text { Total lipid separations efficiency }[-]\end{array}$


$\varphi_{\mathrm{Sep}_{\mathrm{UL}}} \quad$ Useful lipid separations efficiency [-]

$\varphi_{\text {sep }_{\text {TAG }}} \quad$ Triacylglycerol separations efficiency (from total lipids) [-]

$\varphi_{\text {trans }} \quad$ Transesterification efficiency [-]

$\varphi_{\text {post }} \quad$ Post-processing efficiency [-]

LF Lipid fraction [-]

ULF Useful lipid fraction [-]

TAGF Triacylglycerol fraction [-]

$\mathrm{FROI}_{\mathrm{RD}}$ Financial return on investment for renewable diesel $[-]$

\section{Costs}

Production costs per liter of renewable diesel produced

$\widetilde{C}_{\mathrm{G}} \quad$ Cost of growth $\left[\frac{\$}{\mathrm{~L}_{\mathrm{RD}}}\right]$

$\widetilde{C}_{\mathrm{P}} \quad$ Cost of processing $\left[\frac{\$}{\mathrm{~L}_{\mathrm{RD}}}\right]$

$\widetilde{C}_{\mathrm{R}} \quad$ Cost of refining $\left[\frac{\$}{\mathrm{~L}_{\mathrm{RD}}}\right]$

$\widetilde{C}_{\mathrm{H}} \quad$ Cost of harvesting $\left[\frac{\mathrm{s}}{\mathrm{L}_{\mathrm{RD}}}\right]$

$\widetilde{C}_{\mathrm{CL}} \quad$ Cost of cell lysing $\left[\frac{\mathrm{s}}{\mathrm{L}_{\mathrm{RD}}}\right]$

$\widetilde{C}_{\mathrm{S}} \quad$ Cost of separations $\left[\frac{\$}{L_{\mathrm{RD}}}\right]$

$\widetilde{C}_{\mathrm{S}_{\mathrm{L}}} \quad$ Cost of total lipid separations $\left[\frac{\$}{\mathrm{~L}_{\mathrm{RD}}}\right]$

$\widetilde{C}_{\mathrm{SUL}} \quad$ Cost of useful lipid separations $\left[\frac{\$}{\mathrm{~L}_{\mathrm{RD}}}\right]$

$\widetilde{C}_{\mathrm{T}} \quad$ Cost of transesterification $\left[\frac{\$}{\mathrm{~L}_{\mathrm{RD}}}\right]$

$\widetilde{C}_{\mathrm{PP}} \quad$ Cost of post-processing $\left[\frac{\$}{\mathrm{~L}_{\mathrm{RD}}}\right]$

Production costs per kilogram of intermediate product produced by that step

$\widetilde{c}_{\mathrm{G}} \quad$ Cost of growth per kilogram of grown (algal) mass $\left[\frac{\$}{\mathrm{~kg}_{\mathrm{GM}}}\right]$

$\widetilde{c}_{\mathrm{P}} \quad$ Cost of processing per kilogram of biocrude $\left[\frac{\$}{\mathrm{~kg}_{\mathrm{BC}}}\right]$

$\widetilde{c}_{R} \quad$ Cost of refining per kilogram of renewable diesel $\left[\frac{\$}{\mathrm{~kg}_{\mathrm{RD}}}\right]$

$\widetilde{c}_{\mathrm{H}} \quad$ Cost of harvesting per kilogram of harvested (algal) mass $\left[\frac{\$}{\mathrm{~kg}_{\mathrm{HM}}}\right]$

$\widetilde{c}_{\mathrm{CL}} \quad$ Cost of cell lysing per kilogram of lysed (algal) mass $\left[\frac{\$}{\operatorname{kg}_{\mathrm{LM}}}\right]$

$\widetilde{c}_{\mathrm{S}} \quad$ Cost of overall separations per kilogram of separated useful lipid $\left[\frac{\$}{\mathrm{~kg}_{\mathrm{sul}}}\right]$

$\widetilde{c}_{\mathrm{S}_{\mathrm{L}}} \quad$ Cost of total lipid separations per kilogram of separated lipid $\left[\frac{\$}{\mathrm{~kg}_{\mathrm{SL}}}\right]$

$\tilde{c}_{\mathrm{S}_{\mathrm{UL}}} \quad$ Cost of useful lipid separations per kilogram of separated useful lipid $\left[\frac{\$}{\mathrm{~kg}_{\mathrm{SUL}}}\right]$

$\widetilde{c}_{\mathrm{T}} \quad$ Cost of transesterification per kilogram of FAME produced $\left[\frac{\$}{\mathrm{~kg}_{\mathrm{FAME}}}\right]$

$\widetilde{c}_{\mathrm{PP}} \quad$ Cost of post-processing per kilogram of renewable diesel $\left[\frac{\$}{\mathrm{~kg}_{\mathrm{RD}}}\right]$
Cost of intermediate products per liter of renewable diesel

$C_{\mathrm{GM}} \quad$ Cost of grown mass $\left[\frac{\mathrm{S}}{\mathrm{L}_{\mathrm{RD}}}\right]$

$C_{\mathrm{BC}} \quad$ Cost of biocrude mass $\left[\frac{\$}{\mathrm{~L}_{\mathrm{RD}}}\right]$

$C_{\mathrm{HM}} \quad$ Cost of harvested mass $\left[\frac{\$}{\mathrm{~L}_{\mathrm{RD}}}\right]$

$C_{\mathrm{LM}} \quad$ Cost of lysed mass $\left[\frac{\$}{\mathrm{~L}_{\mathrm{RD}}}\right]$

$C_{\mathrm{SUL}} \quad$ Cost of separated useful lipids $\left[\frac{\mathrm{S}}{\mathrm{L}_{\mathrm{RD}}}\right]$

$C_{\mathrm{FAME}}$ Cost of fatty acid methyl esters $\left[\frac{\$}{\mathrm{~L}_{\mathrm{RD}}}\right]$

$C_{\mathrm{RD}} \quad$ Cost of renewable diesel $\left[\frac{\mathrm{s}}{\mathrm{L}_{\mathrm{RD}}}\right]$

Cost of intermediate products per kilogram

$\begin{array}{ll}c_{\mathrm{GM}} & \text { Cost of grown mass }\left[\frac{\$}{\mathrm{~kg}_{\mathrm{GM}}}\right] \\ c_{\mathrm{BC}} & \text { Cost of biocrude mass }\left[\frac{\$}{\mathrm{~kg}_{\mathrm{BC}}}\right] \\ c_{\mathrm{HM}} & \text { Cost of harvested mass }\left[\frac{\$}{\mathrm{~kg}_{\mathrm{HM}}}\right] \\ c_{\mathrm{LM}} & \text { Cost of lysed mass }\left[\frac{\$}{\mathrm{~kg}_{\mathrm{LM}}}\right] \\ c_{\mathrm{SL}} & \text { Cost of separated lipid }\left[\frac{\$}{\mathrm{~kg}}\right] \\ c_{\mathrm{SUL}} & \text { Cost of separated useful lipid }\left[\frac{\$}{\mathrm{~kg} \mathrm{SUL}_{\mathrm{Su}}}\right] \\ c_{\mathrm{FAME}} & \text { Cost of fatty acid methyl esters }\left[\frac{\$}{\mathrm{~kg}}\right] \\ c_{\mathrm{RD}} & \text { Cost of renewable diesel (equivalent to the cost of } \\ & \text { post-processed mass) }\left[\frac{\$}{\mathrm{~kg}}\right]\end{array}$

Energy

LHV Lower heating value $\left[\frac{\mathrm{J}}{\mathrm{kg}}\right]$.

EROI $_{R D}$ Energy return on energy investment for renewable diesel $[-]$

Energy requirements for production per liter of renewable diesel produced

$\widetilde{E}_{\mathrm{G}} \quad$ Energy for growth $\left[\frac{\mathrm{J}}{\mathrm{L}_{\mathrm{RD}}}\right]$

$\widetilde{E}_{\mathrm{P}} \quad$ Energy for processing $\left[\frac{\mathrm{J}}{\mathrm{L}_{\mathrm{DD}}}\right]$

$\widetilde{E}_{\mathrm{R}} \quad$ Energy for refining $\left[\frac{\mathrm{J}}{\mathrm{L}_{\mathrm{RD}}}\right]$

$\widetilde{E}_{\mathrm{H}} \quad$ Energy for harvesting $\left[\frac{\mathrm{J}}{\mathrm{L}_{\mathrm{RD}}}\right]$

$\widetilde{E}_{\mathrm{CL}} \quad$ Energy for cell lysing $\left[\frac{\mathrm{J}}{\mathrm{L}_{\mathrm{RD}}}\right]$

$\widetilde{E}_{\mathrm{S}} \quad$ Energy for overall separations $\left[\frac{\mathrm{J}}{\mathrm{L}_{\mathrm{RD}}}\right]$

$\widetilde{E}_{\mathrm{S}_{\mathrm{L}}} \quad$ Energy for total lipids separations $\left[\frac{\mathrm{J}}{\mathrm{L}_{\mathrm{RD}}}\right]$

$\widetilde{E}_{\mathrm{SUL}} \quad$ Energy for useful lipids separations $\left[\frac{\mathrm{J}}{\mathrm{L}_{\mathrm{RD}}}\right]$

$\widetilde{E}_{\mathrm{T}} \quad$ Energy for transesterification $\left[\frac{\mathrm{J}}{\mathrm{L}_{\mathrm{RD}}}\right]$

$\widetilde{E}_{\mathrm{PP}} \quad$ Energy for post-processing $\left[\frac{\mathrm{J}}{\mathrm{L}_{\mathrm{RD}}}\right]$ 
Energy requirements for production per kilogram of product

$\widetilde{e}_{\mathrm{G}} \quad$ Energy for growth per kilogram of grown mass $\left[\frac{\mathrm{J}}{\mathrm{kg}_{\mathrm{GM}}}\right]$

$\tilde{e}_{\mathrm{P}} \quad$ Energy for processing per kilogram of biocrude $\left[\frac{\mathrm{J}}{\mathrm{kg}_{\mathrm{BC}}}\right]$

$\widetilde{e}_{\mathrm{R}} \quad$ Energy for refining per kilogram of renewable diesel $\left[\frac{\mathrm{J}}{\mathrm{kg}_{\mathrm{RD}}}\right]$

$\widetilde{e}_{\mathrm{H}} \quad$ Energy for harvesting per kilogram of harvested $\operatorname{mass}\left[\frac{\mathrm{J}}{\mathrm{kg}_{\mathrm{HM}}}\right]$

$\widetilde{e}_{\mathrm{CL}} \quad$ Energy for cell lysing per kilogram of lysed mass $\left[\frac{\mathrm{J}}{\mathrm{kg}_{\mathrm{LM}}}\right]$

$\widetilde{e}_{S} \quad$ Energy for separations per kilogram of separated useful lipids $\left[\frac{\mathrm{J}}{\mathrm{kg}_{\mathrm{suL}}}\right]$

$\tilde{e}_{S_{\mathrm{L}}} \quad$ Energy for total lipids separations per kilogram of separated lipids $\left[\frac{\mathrm{J}}{\mathrm{kg}_{\mathrm{SL}}}\right]$

$\widetilde{e}_{\mathrm{SUL}} \quad$ Energy for useful lipids separations per kilogram of separated useful lipids $\left[\frac{\mathrm{J}}{\mathrm{kg}_{\mathrm{sul}}}\right]$

$\widetilde{e}_{\mathrm{T}} \quad$ Energy for transesterification per kilogram of FAME $\left[\frac{\mathrm{J}}{\operatorname{kg}_{\mathrm{FAME}}}\right]$

$\widetilde{e}_{\mathrm{PP}} \quad$ Energy for post-processing per kilogram of renewable diesel $\left[\frac{\mathrm{J}}{\mathrm{kg}_{\mathrm{RD}}}\right]$

Energy requirements for intermediate products per liter of renewable diesel produced

$E_{\mathrm{GM}} \quad$ Energy required for grown mass $\left[\frac{\mathrm{J}}{\mathrm{L}_{\mathrm{RD}}}\right]$

$E_{\mathrm{BC}} \quad$ Energy required for biocrude $\left[\frac{\mathrm{J}}{\mathrm{L}_{\mathrm{RD}}}\right]$

$E_{\mathrm{HM}} \quad$ Energy required for harvested mass $\left[\frac{\mathrm{J}}{\mathrm{L}_{\mathrm{RD}}}\right]$

$E_{\mathrm{LM}} \quad$ Energy required for lysed mass $\left[\frac{\mathrm{J}}{\mathrm{L}_{\mathrm{RD}}}\right]^{L_{\mathrm{RD}}}$

$E_{\mathrm{SUL}} \quad$ Energy required for separated useful lipids $\left[\frac{\mathrm{J}}{\mathrm{L}_{\mathrm{RD}}}\right]$

$E_{\mathrm{FAME}} \quad$ Energy required for fatty acid methyl esters $\left[\frac{\mathrm{J}}{\mathrm{L}_{\mathrm{RD}}}\right]$

$E_{\mathrm{RD}} \quad$ Energy required for renewable diesel $\left[\frac{\mathrm{J}}{\mathrm{L}_{\mathrm{RD}}}\right]$

Energy requirements for intermediate products per kilogram

$e_{\mathrm{GM}} \quad$ Energy required for grown mass $\left[\frac{\mathrm{J}}{\mathrm{kg}_{\mathrm{GM}}}\right]$

$e_{\mathrm{BC}} \quad$ Energy required for biocrude $\left[\frac{\mathrm{J}}{\mathrm{kg}_{\mathrm{BC}}}\right]$

$e_{\mathrm{HM}}$ Energy required for harvested mass $\left[\frac{\mathrm{J}}{\mathrm{kg}_{\mathrm{HM}}}\right]$

$e_{\mathrm{LM}} \quad$ Energy required for lysed mass $\left[\frac{\mathrm{J}}{\mathrm{kg}}\right]$

$e_{\text {SUL }}$ Energy required for separated useful lipids $\left[\frac{\mathrm{J}}{\mathrm{kg}_{\mathrm{SuL}}}\right]$

$e_{\text {FAME }}$ Energy required for fatty acid methyl esters $\left[\frac{\mathrm{J}}{\mathrm{kg}_{\mathrm{FAME}}}\right]$

$e_{\mathrm{RD}} \quad$ Energy required for renewable diesel (equivalent to post-processed mass) $\left[\frac{\mathrm{J}}{\mathrm{kg}}\right]$

Conversion Factors (Dimensionless)

GMCF Grown mass conversion factor [-]

BCCF Biocrude conversion factor [-]

HMCF Harvested mass conversion factor $[-]$
LMCF Lysed mass conversion factor [-]

SLCF Separated lipids conversion factor [-]

SULCF Separated useful lipid conversion factor [-]

FAMECF Fatty acid methyl ester conversion factor [-]

Other

$\rho_{\mathrm{RD}} \quad$ Renewable diesel density $\left[\frac{\mathrm{kg}}{\mathrm{L}}\right]$

\section{Appendix 2}

Detailed Illustration of Nomenclature for Producing Algal Biodiesel via Transesterification of Extracted Lipids

In this Appendix, details of the reporting nomenclature are presented for the production of biodiesel from extracted algal lipids via transesterification to demonstrate the utility of the reporting framework. Biodiesel is a type of renewable diesel, and Fig. 2 presents the general pathway for producing algal biodiesel via transesterification of extracted lipids. This pathway can also be envisioned as the progression of intermediate products, as shown in Fig. 7. The composition of the intermediate products shown might be dynamic, as with any biological system.

The product(s) of each step in the production pathway, shown in Fig. 7, are often complex mixtures of compounds. As a result, the content of each intermediate product may be reported according to the quantity of lipid (all types), neutral lipid, triacylglycerol, hydrocarbon, or FAME present. Thus, it is important to define these terms. Figure 8 outlines a basic classification of lipids, and Fig. 9 provides the chemical structure for a triacylglycerol, a phospholipid, and a FAME. Lipids are broadly defined as naturally produced molecules that are insoluble in water and often characterized as cellular compounds that can be extracted by an organic solvent (e.g., chloroform) [22]. As described by $\mathrm{Hu}$ et al. [97] lipids include polar lipids, neutral lipids, and several additional compounds. Polar lipids, including glycolipids and phospholipids, are a major component in biological membranes [97]. These compounds contain a polar head and non-polar tails that are fat-soluble fatty acids. Neutral lipids, or simple lipids, include non-polar glycerolipids, hydrocarbons, and waxes. A common neutral lipid in microalgae is triacylglycerol (also called triglyceride, TAG, or TG), which is formed as an energy storage product. Triacylglycerol is comprised of a glycerol backbone and three saturated or unsaturated fatty acids. The length and saturation of the fatty acids varies for different algal species [97]. Triacylglycerol produced by microalgae is of particular interest because it is very well suited for biodiesel production due to long fatty acid chains that are 
Fig. 7 There are several intermediate products in the algal biodiesel production pathway. *The total separations efficiency includes the lipids separations efficiency and the useful lipids separation efficiency

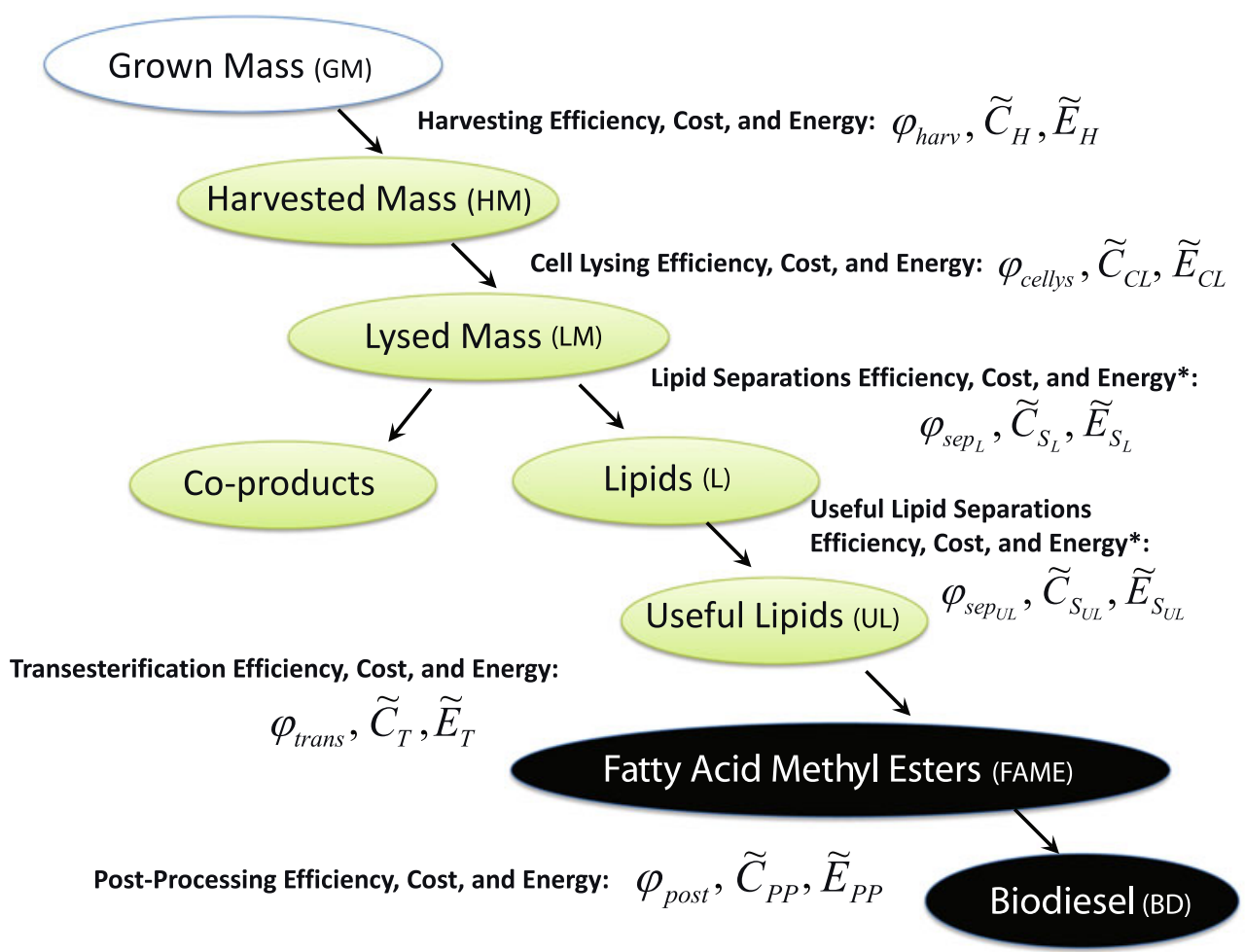

often between 16 and 18 carbon atoms in length (i.e., C:16$\mathrm{C}: 18$, similar to those comprising petroleum diesel) [1, 97]. Also, triacylglycerol does not contain phosphorus or other elements that could complicate biodiesel refining. Some neutral lipids are hydrocarbons, which are defined as molecules consisting exclusively of hydrogen and carbon and are found in several algal species, specifically Botryococcus braunii [98, 112]. FAME, the main components of biodiesel, are produced from lipids via transesterification [36]. The term "useful lipid" is used to refer to the lipids that are compatible with downstream production processes. Generally, triacylglycerol is considered the most useful lipid for biodiesel production. Conversely, phospholipids might complicate refining due to the phosphorus and nitrogen content of the polar head groups, which could prevent them from being used to produce biodiesel. It is not clear which lipids will be useful for industrial scale algal biodiesel production, so triacylglycerol is singled out in some following examples to emphasize the need to be specific about the type of algal lipids that are produced.

\section{Productivity Nomenclature}

Equation 1 can be used to calculate renewable diesel productivity (specifically biodiesel), $P_{\mathrm{RD}}$, which is the rate that renewable diesel can be produced per volume of growth medium, $V_{\mathrm{G}}$. This equation can be expanded to be specific to the production of algal biodiesel from extracted lipids as shown in Eq. 30.

$$
P_{\mathrm{RD}}=\frac{M_{\mathrm{RD}}}{V_{\mathrm{G}} \cdot t_{\mathrm{c}}}=P_{\mathrm{GM}} \cdot \varphi_{\text {harv }} \cdot \varphi_{\text {cellys }} \cdot \varphi_{\text {sep }} \cdot \varphi_{\text {trans }} \cdot \varphi_{\text {post }} \quad\left[\frac{\mathrm{g}}{\overline{\mathrm{L}_{\mathrm{G}} \cdot \mathrm{day}}}\right]
$$

As defined above, $P_{\mathrm{GM}}$ is the grown (algal) mass productivity (g dry algal biomass/(L-day)), $M_{\mathrm{RD}}$ is the mass of renewable diesel produced, $V_{\mathrm{G}}$ is the algal growth volume, and $t_{\mathrm{c}}$ is the cultivation period. The efficiencies listed in Eq. $30, \varphi_{\text {harv }}, \varphi_{\text {cellys }}, \varphi_{\text {sep }}, \varphi_{\text {trans }}$, and $\varphi_{\text {post }}$, are the harvesting, cell lysing, separations, transesterification, and postprocessing efficiencies, respectively (cf. Figs. 2 and 7). As shown in Fig. 2, the harvesting, cell lysing and separations efficiencies are included in the processing phase, and thus, the processing efficiency for this pathway can be defined as

$$
\varphi_{\text {proc }}=\varphi_{\text {harv }} \cdot \varphi_{\text {cellys }} \cdot \varphi_{\text {sep }} \quad[-]
$$

Similarly, the refining phase includes transesterification and post-processing, so the refining efficiency can be expressed as

$$
\varphi_{\text {ref }}=\varphi_{\text {trans }} \cdot \varphi_{\text {post }}[-]
$$

Each efficiency term is defined as the mass of the output product divided by the mass of the input product for that step (cf. Fig. 7). For example, the harvesting efficiency is defined as the amount of harvested dry mass, $M_{\mathrm{HM}}$, divided by the 
Fig. 8 There are several classifications of lipids, some of which are shown here, including neutral and polar lipids. Transesterification is a process that produces fatty acid methyl esters, the major constituent of biodiesel, from lipids
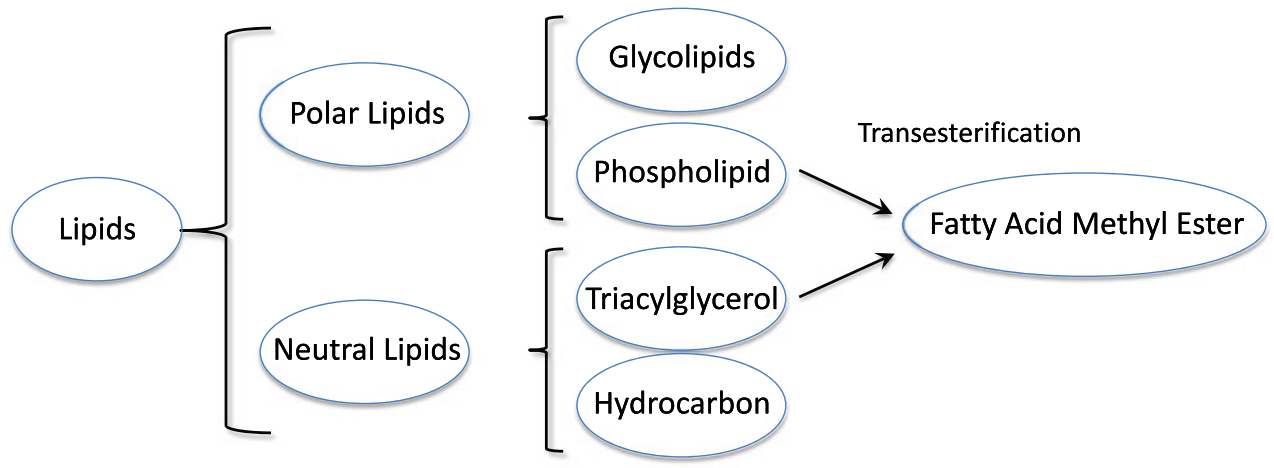

amount of dry grown algal biomass in the growth medium, $M_{\mathrm{GM}}$. The product of harvesting may often be an algal slurry with high water content (often about $90 \%$ water). The harvested dry mass, $M_{\mathrm{HM}}$, is therefore the algal concentration of that product $(\mathrm{g} / \mathrm{L})$ multiplied by the harvested volume $(\mathrm{L})$. The cell lysing efficiency is the lysed dry mass, $M_{\mathrm{LM}}$, divided by the harvested dry mass, $M_{\mathrm{HM}}$.

The separations process may require multiple steps, as shown in Fig. 7. Therefore, the separations efficiency, $\varphi_{\text {sep }}$, is defined as the mass of useful lipids separated, $M_{\mathrm{SUL}}$, divided by the lysed dry mass, $M_{\mathrm{LM}}$. Thus, the separations efficiency incorporates the lipid fraction, LF, the efficiency with which the lipids can be extracted, $\varphi_{\operatorname{sep}_{\mathrm{L}}}$, the useful lipid fraction, ULF, and the efficiency with which the useful lipids can be recovered, $\varphi_{\text {sep }_{\text {UI }}}$, as shown in Eq. 33. The lipid fraction, LF, is defined as the mass of lipids divided by the lysed mass, and the useful lipid fraction, ULF, is defined as mass of useful lipids divided by the mass of the total separated lipids.

$\varphi_{\text {sep }}=\frac{M_{\mathrm{SUL}}}{M_{\mathrm{LM}}}=\mathrm{LF} \cdot \varphi_{\mathrm{sep}_{\mathrm{L}}} \cdot \mathrm{ULF} \cdot \varphi_{\mathrm{sep}_{\mathrm{UL}}} \quad[-]$
For clarity, Eq. 33 can be written in terms of the units for each variable as

$$
\left[\varphi_{\text {sep }}\right] \equiv \frac{\mathrm{kg}_{\mathrm{SUL}}}{\mathrm{kg}_{\mathrm{LM}}} \equiv \frac{\mathrm{kg}_{\mathrm{L}}}{\mathrm{kg}_{\mathrm{LM}}} \cdot \frac{\mathrm{kg}_{\mathrm{SL}}}{\mathrm{kg}_{\mathrm{L}}} \cdot \frac{\mathrm{kg}_{\mathrm{UL}}}{\mathrm{kg}_{\mathrm{SL}}} \cdot \frac{\mathrm{kg}_{\mathrm{SUL}}}{\mathrm{kg}_{\mathrm{UL}}} \quad[-]
$$

where the subscripts refer to separated useful lipids (SUL), lysed mass (LM), lipids (L), total separated lipids (SL), and useful lipids (UL). Variations of this nomenclature can be defined for different production pathways. For instance, for separations processes that accomplish lysing and separations in one step (e.g., solvent extraction), the cell lysing efficiency can be assumed to be 1 and the lipid separations efficiency, $\varphi_{\text {sep }_{\mathrm{L}}}$, can be evaluated as the mass of lipids recovered divided by the harvested (algal) mass used. The subsequent useful lipid separations can then be accounted for with the useful lipid separations efficiency, $\varphi_{\text {sep }_{\text {Ut }}}$.

The terms "separated lipids" and "separated useful lipids" are used explicitly to differentiate the associated productivities, $P_{\mathrm{SL}}$ and $P_{\mathrm{SUL}}$, from the term "lipid productivity," which has been used in the literature to characterize the rate at which algae accumulate lipids within the growth media $[1,41,104,105,107]$. The separated lipid
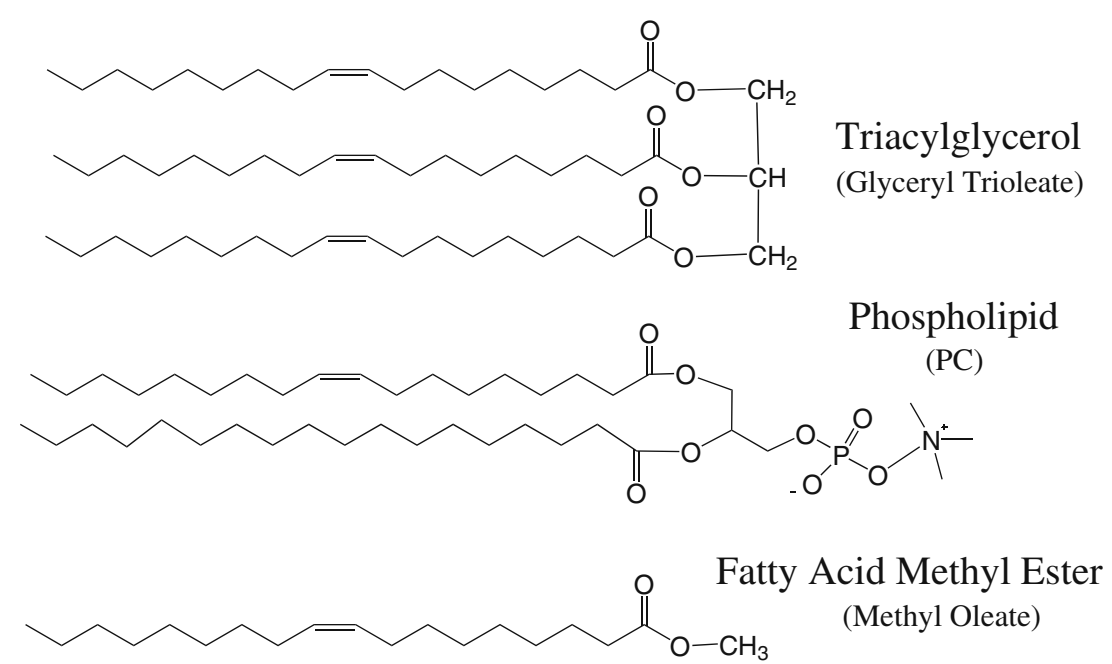

Fig. 9 The chemical structures for a triacylglycerol (specifically, glyceryl trioleate), a phospholipid (specifically, phophotidylcholine), and a fatty acid methyl ester (FAME; specifically, methyl oleate) are shown. Fatty acid methyl esters can be produced from triacylglycerol or phospholipids by transesterification 
productivity and separated useful lipid productivity, on the other hand, indicate the rates at which lipids can be produced from algae including processing efficiencies.

During transesterification, the fatty acids are separated from the lipid backbone (glycerol for triacylglycerol and polar head groups for polar lipids) and the fatty acids acquire a methyl group (from methanol, which is added during transesterification), to become FAME [36, 38]. Thus, the mass of FAME produced by transesterification will differ from the mass of the lipids used for transesterification, a change reflected in the transesterification efficiency. The post-processing efficiency refers to the mass of renewable diesel produced, $M_{\mathrm{RD}}$, divided by the amount of FAME that was produced via transesterification, $M_{\mathrm{FAME}}$. The post-processing efficiency can be greater than 1, depending on post-processing steps and additives, which could increase the total mass of the renewable diesel produced (i.e., processing swell).

The productivity of each intermediate product can be expressed similarly to the renewable diesel productivity shown in Eq. 30 and are shown in Fig. 6.

\section{Cost Nomenclature}

The financial cost of renewable diesel production, $C_{\mathrm{RD}}$, was defined above in Eq. 4 and can be expanded for this production pathway as

$$
C_{\mathrm{RD}}=c_{\mathrm{RD}} \cdot \rho_{\mathrm{RD}}=\widetilde{C}_{\mathrm{G}}+\widetilde{C}_{\mathrm{H}}+\widetilde{C}_{\mathrm{CL}}+\widetilde{C}_{\mathrm{S}}+\widetilde{C}_{\mathrm{T}}+\widetilde{C}_{\mathrm{PP}} \quad\left[\frac{\$}{\mathrm{LD}}\right]
$$

where $\widetilde{C}_{\mathrm{G}}, \widetilde{C}_{\mathrm{H}}, \widetilde{C}_{\mathrm{CL}}, \widetilde{C}_{\mathrm{S}}, \widetilde{C}_{\mathrm{T}}$, and $\widetilde{C}_{\mathrm{PP}}$ refer to the production costs of growth, harvesting, cell lysing, separations, transesterification, and post-processing per liter of renewable diesel, respectively. Recall that a tilde $(\sim)$ is used to differentiate the cost of a production step (i.e., growth, processing, or refining), from the cost of a product (i.e., grown mass, biocrude, or renewable diesel). Also, the lowercase " $c$ " in Eqs. 4 and 35 denotes a cost on a per mass basis. The terms in Eq. 4 can be equated to those in Eq. 35 as

$$
\widetilde{C}_{\mathrm{G}}=\widetilde{C}_{\mathrm{G}} \quad\left[\frac{\$}{\mathrm{~L}_{\mathrm{RD}}}\right]
$$

$$
\widetilde{C}_{\mathrm{P}}=\widetilde{C}_{\mathrm{H}}+\widetilde{C}_{\mathrm{CL}}+\widetilde{C}_{\mathrm{S}} \quad\left[\frac{\$}{\mathrm{~L}_{\mathrm{RD}}}\right]
$$

$$
\widetilde{C}_{\mathrm{R}}=\widetilde{C}_{\mathrm{T}}+\widetilde{C}_{\mathrm{PP}} \quad\left[\frac{\$}{\mathrm{~L}_{\mathrm{RD}}}\right]
$$

The cost of growth was defined above as that in Eq. 5, and in this pathway, the grown mass conversion factor, GMCF, can be expressed as

$$
\mathrm{GMCF}=\frac{1}{\varphi_{\text {harv }}} \cdot \frac{1}{\varphi_{\text {cellys }}} \cdot \frac{1}{\varphi_{\text {sep }}} \cdot \frac{1}{\varphi_{\text {trans }}} \cdot \frac{1}{\varphi_{\text {post }}} \quad\left[\frac{\mathrm{kg}_{\mathrm{GM}}}{\mathrm{kg}_{\mathrm{RD}}}\right]
$$

To clarify, GMCF is written in terms of the units of each term in Eq. 39 as

$$
[\mathrm{GMCF}] \equiv \frac{\mathrm{kg}_{\mathrm{GM}}}{\mathrm{kg}_{\mathrm{RD}}} \equiv \frac{\mathrm{kg}_{\mathrm{GM}}}{\mathrm{kg}_{\mathrm{HM}}} \cdot \frac{\mathrm{kg}_{\mathrm{HM}}}{\mathrm{kg}_{\mathrm{LM}}} \cdot \frac{\mathrm{kg}_{\mathrm{LM}}}{\mathrm{kg}_{\mathrm{SUL}}} \cdot \frac{\mathrm{kg}_{\mathrm{SUL}}}{\mathrm{kg}_{\mathrm{FAME}}} \cdot \frac{\mathrm{kg}_{\mathrm{FAME}}}{\mathrm{kg}_{\mathrm{RD}}}
$$

Similarly, the cost of harvesting per liter of renewable diesel, $\left(\widetilde{C}_{\mathrm{H}}\right)$, can be written as

$$
\widetilde{C}_{\mathrm{H}}=\widetilde{c}_{\mathrm{H}} \cdot \mathrm{HMCF} \cdot \rho_{\mathrm{RD}} \quad\left[\frac{\$}{\mathrm{~L}_{\mathrm{RD}}}\right]
$$

where $\widetilde{c}_{\mathrm{H}}$ is the cost of the harvesting process per kilogram of harvested (algal) dry mass (the tilde indicates a processing step cost) and $\mathrm{HMCF}$ is the harvested mass conversion factor. The HMCF is the amount of harvested (algal) dry mass needed to produce an associated amount of renewable diesel, and for this pathway, it is defined as

$$
\mathrm{HMCF}=\frac{1}{\varphi_{\text {cellys }}} \cdot \frac{1}{\varphi_{\text {sep }}} \cdot \frac{1}{\varphi_{\text {trans }}} \cdot \frac{1}{\varphi_{\text {post }}} \quad\left[\frac{\mathrm{kg}_{\mathrm{HM}}}{\mathrm{kg}_{\mathrm{RD}}}\right]
$$

The relationship between GMCF and HMCF is, thus,

$\mathrm{GMCF}=\frac{1}{\varphi_{\text {harv }}} \cdot \mathrm{HMCF}$

The cell lysing, separations, transesterification, and postprocessing costs can be expanded similarly. For instance, the cost of lysing algal biomass per liter of renewable diesel can be written as

$$
\widetilde{C}_{\mathrm{CL}}=\widetilde{c}_{\mathrm{CL}} \cdot \mathrm{LMCF} \cdot \rho_{\mathrm{RD}} \quad\left[\frac{\$}{\mathrm{~L}_{\mathrm{RD}}}\right]
$$

where $\widetilde{c}_{\mathrm{CL}}$ is the cost of the cell lysing process per kilogram of lysed dry mass and LMCF is the lysed mass conversion factor, which can be expressed as

$$
\mathrm{LMCF}=\frac{1}{\varphi_{\text {sep }}} \cdot \frac{1}{\varphi_{\text {trans }}} \cdot \frac{1}{\varphi_{\text {post }}} \quad\left[\frac{\mathrm{kg}_{\mathrm{g}}}{\mathrm{kg}_{\mathrm{RD}}}\right]
$$

The LMCF is the amount of lysed algal biomass needed to produce an associated amount of renewable diesel. Continuing this process, Eq. 46 presents the separations cost, $\widetilde{C}_{\mathrm{S}}$, which might include multiple separation steps (cf. Fig. 7).

$$
\widetilde{C}_{\mathrm{s}}=\widetilde{c}_{\mathrm{S}} \cdot \mathrm{SULCF} \cdot \rho_{\mathrm{RD}} \quad\left[\frac{\$}{\mathrm{~L}_{\mathrm{RD}}}\right]
$$


In Eq. $46, \widetilde{c}_{\mathrm{S}}$ is the separations cost per kilogram of separated useful lipids and SULCF is the separated useful lipids conversion factor, which can be written as

$$
\mathrm{SULCF}=\frac{1}{\varphi_{\text {trans }}} \cdot \frac{1}{\varphi_{\text {post }}} \quad\left[\frac{\mathrm{kg}_{\mathrm{SUL}}}{\mathrm{kg}_{\mathrm{RD}}}\right]
$$

Since many processes extract an assortment of lipids that might or might not be useful (sometimes called "algal oil"), it is worth expanding the separations cost to account for the difference between lipids and useful lipids, as shown in Eq. 48.

$$
\begin{aligned}
\widetilde{C}_{\mathrm{S}}= & \widetilde{C}_{\mathrm{S}_{\mathrm{L}}}+\widetilde{C}_{\mathrm{S}_{\mathrm{UL}}}=\left(\widetilde{c}_{\mathrm{S}_{\mathrm{L}}} \cdot \mathrm{SLCF} \cdot \rho_{\mathrm{RD}}\right) \\
& +\left(\widetilde{c}_{\mathrm{S}_{\mathrm{UL}}} \cdot \mathrm{SULCF} \cdot \rho_{\mathrm{RD}}\right) \quad\left[\frac{\$}{\mathrm{~L}_{\mathrm{RD}}}\right]
\end{aligned}
$$

In Eq. $48, \widetilde{C}_{\mathrm{S}_{\mathrm{L}}}$ is the cost of separating all lipids from the other biomass and $\widetilde{C}_{\mathrm{S}_{U L}}$ is the subsequent separations cost to isolate useful lipids (cf. Fig. 7). The cost of the initial lipid separations per kilogram of total separated lipids is $\widetilde{c}_{\mathrm{S}_{\mathrm{SL}}}$, and the cost of separating useful lipids from the total lipids per kilogram of separated useful lipids is $\widetilde{c}_{\mathrm{S}_{\mathrm{UL}}}$. Finally, SLCF is the separated lipids conversion factor, which is the mass of separated lipids needed to produce an associated amount of renewable diesel and can be written as

$\mathrm{SLCF}=\frac{1}{\mathrm{ULF}} \cdot \frac{1}{\varphi_{\text {sepuL }}} \cdot \frac{1}{\varphi_{\text {trans }}} \cdot \frac{1}{\varphi_{\text {post }}} \quad\left[\frac{\mathrm{kg}_{\mathrm{SL}}}{\mathrm{kg}_{\mathrm{RD}}}\right]$

The transesterification cost can be represented as

$$
\widetilde{C}_{\mathrm{T}}=\widetilde{c}_{\mathrm{T}} \cdot \mathrm{FAMECF} \cdot \rho_{\mathrm{RD}} \quad\left[\frac{\$}{\mathrm{~L}_{\mathrm{RD}}}\right]
$$

with $\widetilde{c}_{\mathrm{T}}$ being the cost of transesterification in dollars per kilogram of FAME. The FAME conversion factor, FAMECF, can be defined as

$\mathrm{FAMECF}=\frac{1}{\varphi_{\text {post }}} \quad\left[\frac{\mathrm{kg}_{\mathrm{FAME}}}{\mathrm{kg}_{\mathrm{RD}}}\right]$
Finally, the cost of post-processing, $\widetilde{C}_{\mathrm{PP}}$, can be written as

$$
\widetilde{C}_{\mathrm{PP}}=\widetilde{c}_{\mathrm{PP}} \cdot \rho_{\mathrm{RD}} \quad\left[\frac{\$}{\mathrm{~L}_{\mathrm{RD}}}\right]
$$

where $\widetilde{c}_{\mathrm{PP}}$ is the cost of post-processing per kilogram of biodiesel that is produced.

It might be convenient for cost analyses to be reported in units of dollars per kilogram of intermediate product, as shown in Table 4. Each of these equations can be conceptualized as the sum of the cost for producing the input product of that processing step (per kilogram of the output product) and the cost of the processing step (per kilogram of the output product). For example, the cost of FAME, per kilogram of FAME, is the cost of producing separated useful lipids (per kilogram of FAME, a unit conversion that requires $\varphi_{\text {trans }}$ ) plus the cost of transesterification (per kilogram of FAME). Multiple examples of this cost nomenclature were presented above in "Use of Symbolic Notation" under "Framework Principles" section.

\section{Energy Consumption Nomenclature}

The energy required to produce renewable diesel, $E_{\mathrm{RD}}$, was defined in Eq. 11, which can be expanded for this production pathway as

$$
E_{\mathrm{RD}}=\widetilde{E}_{\mathrm{G}}+\widetilde{E}_{\mathrm{H}}+\widetilde{E}_{\mathrm{CL}}+\widetilde{E}_{\mathrm{S}}+\widetilde{E}_{\mathrm{T}}+\widetilde{E}_{\mathrm{PP}} \quad\left[\frac{\mathrm{J}}{\mathrm{L}_{\mathrm{RD}}}\right]
$$

where $\widetilde{E}_{\mathrm{G}}, \widetilde{E}_{\mathrm{H}}, \widetilde{E}_{\mathrm{CL}}, \widetilde{E}_{\mathrm{S}}, \widetilde{E}_{\mathrm{T}}$, and $\widetilde{E}_{\mathrm{PP}}$ are the energy requirements for growth, harvesting, cell lysing, separations, transesterification, and post-processing per liter of renewable diesel, respectively (cf. Figs. 2 and 7). Recall that the tilde indicates the energy cost of a production step. The terms in Eq. 11 can be equated to those in Eq. 53 as

$$
\widetilde{E}_{\mathrm{G}}=\widetilde{E}_{\mathrm{G}} \quad\left[\frac{\mathrm{J}}{\mathrm{L}_{\mathrm{RD}}}\right]
$$

\begin{tabular}{|c|c|c|}
\hline & Financial costs & Energy requirements \\
\hline Grown mass & $c_{\mathrm{GM}}=\widetilde{c}_{\mathrm{G}} \quad\left[\frac{\varsigma}{\mathrm{kg}_{\mathrm{GM}}}\right]$ & $e_{\mathrm{GM}}=\widetilde{e}_{\mathrm{G}} \quad\left[\frac{\mathrm{J}}{\mathrm{kg}_{\mathrm{GM}}}\right]$ \\
\hline Harvested mass & $c_{\mathrm{HM}}=c_{\mathrm{GM}} \cdot \frac{1}{\varphi_{\text {harv }}}+\widetilde{c}_{\mathrm{H}} \quad\left[\frac{\$}{\mathrm{~kg}_{\mathrm{HM}}}\right]$ & $e_{\mathrm{HM}}=e_{G M} \cdot \frac{1}{\varphi_{\text {harv }}}+\widetilde{e}_{H} \quad\left[\frac{\mathrm{J}}{\mathrm{kg}_{\mathrm{HM}}}\right]$ \\
\hline Lysed mass & $c_{\mathrm{LM}}=c_{\mathrm{HM}} \cdot \frac{1}{\varphi_{\text {cellys }}}+\widetilde{c}_{\mathrm{CL}} \quad\left[\frac{\$}{\mathrm{~kg}_{\mathrm{LM}}}\right]$ & $e_{\mathrm{LM}}=e_{\mathrm{HM}} \cdot \frac{1}{\varphi_{\text {cellys }}}+\widetilde{e}_{\mathrm{CL}} \quad\left[\frac{\mathrm{J}}{\mathrm{kg}_{\mathrm{LM}}}\right]$ \\
\hline Separated lipids & $c_{\mathrm{SL}}=c_{\mathrm{LM}} \cdot \frac{1}{\varphi_{\mathrm{sep}}}+\widetilde{c}_{\mathrm{S}_{\mathrm{L}}} \quad\left[\frac{\$}{\mathrm{~kg}_{\mathrm{SL}}}\right]$ & $e_{\mathrm{SL}}=e_{\mathrm{LM}} \cdot \frac{1}{\varphi_{\mathrm{sep}_{\mathrm{L}}}}+\widetilde{e}_{\mathrm{S}_{\mathrm{L}}}$ \\
\hline Separated useful lipids & $c_{\mathrm{SUL}}=c_{\mathrm{LM}} \cdot \frac{1}{\varphi_{\mathrm{sep}}}+\widetilde{c}_{\mathrm{S}} \quad\left[\frac{\$}{\mathrm{~kg}_{\mathrm{SuL}}}\right]$ & $e_{\mathrm{SUL}}=e_{\mathrm{LM}} \cdot \frac{1}{\varphi_{\mathrm{sep}}}+\widetilde{e}_{\mathrm{S}}$ \\
\hline FAME & $c_{\mathrm{FAME}}=c_{\mathrm{SUL}} \cdot \frac{1}{\varphi_{\text {trans }}}+\widetilde{c}_{\mathrm{T}} \quad\left[\frac{\$}{\mathrm{~kg}_{\mathrm{FAME}}}\right]$ & $e_{\mathrm{FAME}}=e_{\mathrm{SUL}} \cdot \frac{1}{\varphi_{\text {trans }}}+\widetilde{e}_{E}$ \\
\hline Biodiesel & $c_{\mathrm{BD}}=c_{\mathrm{FAME}} \cdot \frac{1}{\varphi_{\text {post }}}+\widetilde{c}_{\mathrm{PP}} \quad\left[\frac{\$}{\mathrm{~kg}_{\mathrm{BD}}}\right]$ & $e_{\mathrm{BD}}=e_{\mathrm{FAME}} \cdot \frac{1}{\varphi_{\mathrm{post}}}+\widetilde{e}_{\mathrm{PP}}$ \\
\hline
\end{tabular}

Table 4 Intermediate product costs and energy requirements for the transesterification of algal lipids production pathway 
$\widetilde{E}_{\mathrm{P}}=\widetilde{E}_{\mathrm{H}}+\widetilde{E}_{\mathrm{CL}}+\widetilde{E}_{\mathrm{S}} \quad\left[\frac{\mathrm{J}}{\mathrm{L}_{\mathrm{RD}}}\right]$

$\widetilde{E}_{\mathrm{R}}=\widetilde{E}_{\mathrm{T}}+\widetilde{E}_{\mathrm{PP}} \quad\left[\frac{\mathrm{J}}{\mathrm{L}_{\mathrm{RD}}}\right]$

As shown above, a top-level definition of the EROI associated with renewable diesel production (not including capital energy expense), $\mathrm{EROI}_{\mathrm{RD}}$, can be defined as that in Eq. 15. The accuracy of the final result depends greatly on the specificity and level of inclusion used when calculating the energy cost of each input. For example, Benemann and Oswald provide a template for calculating the growth energy, $\widetilde{E}_{\mathrm{G}}$, in large-scale production facilities by including energy for mixing, water supply, and nutrient supply [22]. Additional detail can be afforded for studies with a smaller scope (Beal et al. 2010 [113]). It would be appropriate if primary researchers report the energy associated with their analyses, such as the energy required for growth per liter of renewable diesel, $\widetilde{E}_{\mathrm{G}}$, in great detail. Practically, this information may be most effectively reported as

$$
\widetilde{E}_{\mathrm{G}}=\widetilde{e}_{\mathrm{G}} \cdot \mathrm{GMCF} \cdot \rho_{\mathrm{RD}} \quad\left[\frac{\mathrm{J}}{\mathrm{L}_{\mathrm{RD}}}\right]
$$

where $\widetilde{e}_{\mathrm{G}}$ is the energy required for growth per kilogram of grown (algal) dry mass, $\rho_{\mathrm{RD}}$ is the renewable diesel density $(\mathrm{kg} / \mathrm{L})$, and GMCF is the grown mass conversion factor, as defined in Eq. 39. The GMCF might be unknown and, therefore, left in symbolic notation, as discussed further in "Use of Symbolic Notation" section. In a similar way, the other terms in Eq. 53 can be defined as

$$
\begin{aligned}
& \widetilde{E}_{\mathrm{H}}=\widetilde{e}_{\mathrm{H}} \cdot \mathrm{HMCF} \cdot \rho_{\mathrm{RD}} \quad\left[\frac{\mathrm{J}}{\mathrm{L}_{\mathrm{RD}}}\right] \\
& \widetilde{E}_{\mathrm{CL}}=\widetilde{e}_{\mathrm{CL}} \cdot \mathrm{LMCF} \cdot \rho_{\mathrm{RD}} \quad\left[\frac{\mathrm{J}}{\mathrm{L}_{\mathrm{RD}}}\right] \\
& \widetilde{E}_{\mathrm{S}}=\widetilde{e}_{\mathrm{S}} \cdot \mathrm{SULCF} \cdot \rho_{\mathrm{RD}} \quad\left[\frac{\mathrm{J}}{\mathrm{L}_{\mathrm{RD}}}\right] \\
& \widetilde{E}_{\mathrm{T}}=\widetilde{e}_{\mathrm{T}} \cdot \mathrm{FAMECF} \cdot \rho_{\mathrm{RD}} \quad\left[\frac{\mathrm{J}}{\mathrm{L}_{\mathrm{RD}}}\right] \\
& \widetilde{E}_{\mathrm{PP}}=\widetilde{e}_{\mathrm{PP}} \cdot \rho_{\mathrm{RD}} \quad\left[\frac{\mathrm{J}}{\mathrm{L}_{\mathrm{RD}}}\right]
\end{aligned}
$$

where $\widetilde{e}_{\mathrm{H}}, \widetilde{e}_{\mathrm{CL}}, \widetilde{e}_{\mathrm{S}}, \widetilde{e}_{\mathrm{T}}$, and $\widetilde{e}_{\mathrm{PP}}$ are the energy requirements for each production step (harvesting $(\mathrm{H})$, cell lysing $(\mathrm{CL})$, separations (S), transesterification (T), and post-processing (PP)) per kilogram of the output of that production step (harvested dry mass, lysed dry mass, separated useful lipids,
FAME, and biodiesel, respectively). Note, again, that the tilde indicates a production step cost. To be consistent, the separations energy requirement can be expanded (similar to the separations cost expansion shown in Eq. 48) as

$$
\begin{aligned}
\widetilde{E}_{\mathrm{S}}= & \widetilde{E}_{\mathrm{S}_{\mathrm{L}}}+\widetilde{E}_{\mathrm{SUL}}=\left(\widetilde{e}_{\mathrm{S}_{\mathrm{L}}} \cdot \mathrm{SLCF} \cdot \rho_{\mathrm{BD}}\right) \\
& +\left(\widetilde{e}_{\mathrm{SUL}} \cdot \mathrm{SULCF} \cdot \rho_{\mathrm{BD}}\right) \quad\left[\frac{\mathrm{J}}{\mathrm{L}_{\mathrm{BD}}}\right]
\end{aligned}
$$

where the subscripts "L" and "UL" refer to the total lipid separations step and the useful lipid separations step, respectively (cf. Fig. 7). It may be more convenient to report energy consumption on a mass basis for each intermediate product, as shown in Table 4.

\section{References}

1. Sheehan J et al. (1998) A look back at the U.S. Department of Energy's Aquatic Species Program-biodiesel from algae. NREL and US Department of Energy's Office of Fuels Development. NREL/TP-580-24190

2. Hallenbeck P, Benemann J (2002) Biological hydrogen production; fundamentals and limiting processes. Int $\mathrm{J}$ Hydrogen Energy 27(11-12):1185-1193

3. Berberoglu H, Jay J, Pilon L (2008) Effect of nutrient media on photobiological hydrogen production by Anabaena variabilis ATCC 29413. Int J Hydrogen Energy 33(4):1172-1184

4. Berberoglu $\mathrm{H}$ et al (2008) Growth, $\mathrm{CO}_{2}$ consumption and $\mathrm{H}_{2}$ production of Anabaena variabilis ATCC 29413-U under different irradiances and $\mathrm{CO}_{2}$ concentrations. J Appl Microbiol 104(1):105-121

5. Tsukahara K, Sawayama S (2005) Liquid fuel production using microalgae. J Jpn Pet Inst 48(5):251

6. Yen H, Brune DE (2007) Anaerobic co-digestion of algal sludge and waste paper to produce methane. Bioresour Technol 98 (1):130-134

7. Sialve B, Bernet N, Bernard O (2008) Anaerobic digestion of microalgae as a necessary step to make microalgal biodiesel sustainable. Biotechnol Adv 27(4):409-416

8. Ni M et al (2006) An overview of hydrogen production from biomass. Fuel Process Technol 87(5):461-472

9. Posten C, Schaub G (2009) Microalgae and terrestrial biomass as source for fuels - a process view. J Biotechnol 142(1):64-69

10. Borowitzka M (1988) Fats, oils and hydrocarbons. In: Borowitzka MA, Borowitzka LJ (eds) Micro-algal biotechnology. Cambridge University Press, Cambridge, pp 257-287

11. Amin S (2009) Review on biofuel oil and gas production processes from microalgae. Energy Convers Manage 50(7):1834-1840

12. Brennan L, Owende P (2010) Biofuels from microalgae-a review of technologies for production, processing, and extractions of biofuels and co-products. Renewable Sustainable Energy Rev 14(2):557-577

13. Sheehan J et al (2000) An overview of biodiesel and petroleum diesel life cycles. NREL, Golden, CO, NREL/TP-580-24772

14. National Renewable Energy Laboratory (2009) Nonpetroleum based fuels. http://www.nrel.gov/vehiclesandfuels/npbf/renewable diesel.html

15. Haas MJ et al (2006) A process model to estimate biodiesel production costs. Bioresour Technol 97(4):671-678 
16. Schenk P et al (2008) Second generation biofuels: highefficiency microalgae for biodiesel production. BioEnergy Res 1(1):20-43

17. Chisti Y (2007) Biodiesel from microalgae. Biotechnol Adv 25 (3):294-306

18. Li X, Xu H, Wu Q (2007) Large-scale biodiesel production from microalga Chlorella protothecoides through heterotrophic cultivation in bioreactors. Biotechnol Bioeng 98(4):764-771

19. Miao X, Wu Q (2006) Biodiesel production from heterotrophic microalgal oil. Bioresour Technol 97(6):841-846

20. Molina Grima E et al (2003) Recovery of microalgal biomass and metabolites: process options and economics. Biotechnol Adv 20(7-8):491-515

21. Tornabene TG et al (1983) Lipid composition of the nitrogen starved green alga Neochloris oleoabundans. Enzyme Microb Technol 5(6):435-440

22. Benemann J, Oswald W (1996) Systems and economic analysis of microalgae ponds for conversion of $\mathrm{CO}_{2}$ to biomass. US Department of Energy, Washington, DC

23. Henderson R, Parsons S, Jefferson B (2008) The impact of algal properties and pre-oxidation on solid-liquid separation of algae. Water Res 42(8-9):1827-1845

24. Poelman E, De Pauw N, Jeurissen B (1997) Potential of electrolytic flocculation for recovery of micro-algae. Resour Conserv Recycl 19:1-10

25. Csordas A, Wang J (2004) An integrated photobioreactor and foam fractionation unit for the growth and harvest of Chaetoceros spp. in open systems. Aquacult Eng 30(1-2):15-30

26. Divakaran R, Pillai VNS (2002) Flocculation of algae using chitosan. J Appl Phycol 14(5):419-422

27. Nagle N, Lemke P (1990) Production of methyl ester fuel from microalgae. Appl Biochem Biotechnol 24-25(1):355-361

28. Shelef GA, Sukenik A, Green M (1984) Microalgae harvesting and processing: a literature review. Report, Solar Energy Research Institute, Golden Colorado, SERI/STR-231-2396

29. Neumann E, Sowers A, Jordan C (eds) (1989) Electroporation and electrofusion in cell biology. Plenum, New York

30. Lee $J$ et al (2010) Comparison of several methods for effective lipid extraction from microalgae. Bioresour Technol 101(1, Supplement 1):S75-S77

31. Lee S, Yoon B, Oh H (1998) Rapid method for the determination of lipid from the green alga Botryococcus braunii. Biotechnol Tech 12(7):553-556

32. Mendes R et al (1995) Supercritical $\mathrm{CO}_{2}$ extraction of carotenoids and other lipids from Chlorella vulgaris. Food Chem 53(1):99-103

33. Aresta $\mathrm{M}$ et al (2005) Production of biodiesel from macroalgae by supercritical $\mathrm{CO} 2$ extraction and thermochemical liquefaction. Environ Chem Lett 3(3):136-139

34. Choi KJ et al (1987) Supercritical fluid extraction and characterization of lipids from algae scenedesmus obliquus. Food Biotechnol 1(2):263-281

35. Seibert AF (2009) Enhanced coalescence. Personal communication, Beal CM, University of Texas at Austin, Austin, TX

36. Durrett T, Benning C, Ohlrogge J (2008) Plant triacylglycerols as feedstocks for the production of biofuels. Plant J 54(4):593607

37. Huang $G$ et al (2010) Biodiesel production by microalgal biotechnology. Appl Energy 87(1):38-46

38. Demirbas A (2009) Progress and recent trends in biodiesel fuels. Energy Convers Manage 50(1):14-34

39. Um BH, Kim YS (2009) Review: a chance for Korea to advance algal-biodiesel technology. J Ind Eng Chem 15(1):1-7

40. Meher LC, Vidya Sagar D, Naik SN (2006) Technical aspects of biodiesel production by transesterification - a review. Renewable Sustainable Energy Rev 10(3):248-268
41. Griffiths M, Harrison S (2009) Lipid productivity as a key characteristic for choosing algal species for biodiesel production. J Appl Phycol 21:493-507

42. Borowitzka M (1992) Algal biotechnology products and processes - matching science and economics. J Appl Phycol 4 (3):267-279

43. Gordon J, Polle J (2007) Ultrahigh bioproductivity from algae. Appl Microbiol Biotechnol 76(5):969-975

44. Moheimani N, Borowitzka M (2006) The long-term culture of the coccolithophore Pleurochrysis carterae (Haptophyta) in outdoor raceway ponds. J Appl Phycol 18(6):703-712

45. Tester JW et al (2005) Sustainable energy: choosing among options. MIT, Cambridge

46. Smil V (2005) Energy at the crossroads: global perspectives and uncertainties. MIT, Cambridge

47. Mulder K, Hagens NJ (2009) Energy return on investment: toward a consistent framework. AMBIO J Hum Environ 37 (2):74-79

48. Macedo IC, Seabra JEA, Silva JEAR (2008) Green house gases emissions in the production and use of ethanol from sugarcane in Brazil: the 2005/2006 averages and a prediction for 2020 . Biomass Bioenergy 32(7):582-595

49. Hagens NJ, Mulder K (2008) A framework for energy alternatives: net energy, Liebig's law and multi-criteria analysis. In: Pimentel D (ed) Biofuels, solar and wind as renewable energy systems. Springer, Dordrecht, pp 295319

50. Poldy F (2008) Net energy and strategic decision-making. Biofuels, Bioprod Biorefin 2(5):389-392

51. Clarens AF et al (2010) Environmental life cycle comparison of algae to other bioenergy feedstocks. Environ Sci Technol 44 (5):1813-1819

52. Cleveland CJ (2005) Net energy from the extraction of oil and gas in the United States. Energy 30(5):769-782

53. Cleveland CJ et al (1984) Energy and the U.S. Economy: a biophysical perspective. Science 225(4665):890-897

54. Pimentel D, Patzek TW (2005) Ethanol production using corn, switchgrass, and wood; biodiesel production using soybean and sunflower. Nat Resour Res 14(1):65-76

55. Kreith F, West R (2004) Fallacies of a hydrogen economy: a critical analysis of hydrogen production and utilization. J Energy Res Technol 126(4):249-257

56. Yang YF et al (2004) Analysis of energy conversion characteristics in liquefaction of algae. Resour Conserv Recycl 43(1):21-33

57. Minowa $\mathrm{T}$ et al (1995) Oil production from algal cells of Dunaliella tertiolecta by direct thermochemical liquefaction. Fuel 74(12):1735-1738

58. Sawayama S, Minowa T, Yokoyama SY (1999) Possibility of renewable energy production and $\mathrm{CO}_{2}$ mitigation by thermochemical liquefaction of microalgae. Biomass Bioenergy 17 (1):33-39

59. Peng W, Wu Q, Tu P (2000) Effects of temperature and holding time on production of renewable fuels from pyrolysis of Chlorella protothecoides. J Appl Phycol 12(2):147-152

60. Antal MJ Jr, Matsumura Y, Xu X (1995) Catalytic gasification of wet biomass in supercritical water. In: Preprints of Papers, American Chemical Society, Division of Fuel Chemistry, vol 40, issue 2, conference 209. American Chemical Society (ACS) National Meeting, Anaheim, CA, USA, 2-6 Apr 1995. Other information PBD: 1995, 1995: p. pp. 304-307

61. Chakinala AG et al (2009) Catalytic and non-catalytic supercritical water gasification of microalgae and glycerol. Ind Eng Chem Res 49(3): 1113-1122

62. Demirbas A (2010) Hydrogen from mosses and algae via pyrolysis and steam gasification. Energy Sources A 32(2):172179 
63. Hirano A et al (1998) Temperature effect on continuous gasification of microalgal biomass: theoretical yield of methanol production and its energy balance. Catal Today 45(1-4):399-404

64. Zou S et al (2009) Thermochemical catalytic liquefaction of the marine microalgae Dunaliella tertiolecta and characterization of bio-oils. Energy Fuels 23:3753-3758

65. Dote Y et al (1994) Recovery of liquid fuel from hydrocarbonrich microalgae by thermochemical liquefaction. Fuel 73 (12):1855-1857

66. Ikenaga $\mathrm{N}$ et al (2001) Co-liquefaction of micro algae with coal using coal liquefaction catalysts. Energy Fuels 15(2):350-355

67. Matsui $\mathrm{T}$ et al (1997) Liquefaction of micro-algae with iron catalyst. Fuel 76(11):1043-1048

68. Synthetic Genomics Inc (2009) Next generation fuels and chemicals. http://www.syntheticgenomics.com/what/renewablefuels.html. Accessed 9 Nov 2009

69. Roessler PG et al. (2009) Secretion of fatty acids by photosynthetic microorganisms. In: WIP Organization (ed). WO/2009/ 076559. Synthetic Genomics, La Jolla, CA

70. Briggs $\mathrm{S}$ et al. (2009) Molecule production by photosynthetic organisms. In: WIP Organization (ed). WO/2009/036067. Sapphire Energy, San Diego, CA

71. Trimbur DE et al. (2008) Production of oil in microorganisms. In: WIP Organization (ed). WO/2008/151149. Solazyme, South San Francisco, $\mathrm{Ca}$

72. Hejazi MA, Wijffels RH (2004) Milking of microalgae. Trends Biotechnol 22(4):189-194

73. Ramachandra TV et al (2009) Milking diatoms for sustainable energy: biochemical engineering versus gasoline-secreting diatom solar panels. Ind Eng Chem Res 48(19):8769-8788

74. ARPA-E US Department of Energy. Cyanobacteria designed for solar-power highly efficient production of biofuels. http://arpa-e. energy.gov/projects/sf.html. Accessed Nov 2009

75. OriginOil. Live Extraction ${ }^{\mathrm{TM}}$. http://www.originoil.com/technology/ live-extraction.html. Accessed Nov 2009

76. Rosenberg JN et al (2008) A green light for engineered algae: redirecting metabolism to fuel a biotechnology revolution. Curr Opin Biotechnol 19(5):430-436

77. Demirbas A (2000) Mechanisms of liquefaction and pyrolysis reactions of biomass. Energy Convers Manage 41(6):633646

78. Goyal HB, Seal D, Saxena RC (2008) Bio-fuels from thermochemical conversion of renewable resources: a review. Renewable Sustainable Energy Rev 12(2):504-517

79. Tran NH et al (2010) Catalytic upgrading of biorefinery oil from micro-algae. Fuel 89(2):265-274

80. Milne TA, Elam CC, Evans RJ (2002) Hydrogen from biomass: state of the art and research challenges, in Report to International Energy Agency: IEA/H2-TR-02/001, p. 82

81. Spath PL, Dayton DC (2003) Preliminary screening - technical and economic assessment of synthesis gas to fuels and chemicals with emphasis on the potential for biomass-derived syngas. National Renewable Energy Laboratory, Golden, CO, NREL/TP 510-34929

82. Demirbas A (2007) Progress and recent trends in biofuels. Prog Energy Combust Sci 33(1):1-18

83. Li Y et al (2008) Biofuels from microalgae. Biotechnol Prog 24 (4):815-820

84. Chum HL, Overend RP (2001) Biomass and renewable fuels. Fuel Process Technol 71(1-3):187-195

85. Lardon L et al (2009) Life-Cycle assessment of biodiesel production from microalgae. Environ Sci Technol 43(17):6475-6481

86. Chisti Y (2008) Biodiesel from microalgae beats bioethanol. Trends Biotechnol 26(3):126-131

87. Li Q, Du W, Liu D (2008) Perspectives of microbial oils for biodiesel production. Appl Microbiol Biotechnol 80(5):749-756
88. Wyman CE, Goodman BJ (1993) Biotechnology for production of fuels, chemicals, and materials from biomass. Appl Biochem Biotechnol 39:41-59

89. Sharma YC, Singh B (2009) Development of biodiesel: current scenario. Renewable Sustainable Energy Rev 13(6-7):16461651

90. Vyas AP, Verma JL, Subrahmanyam N (2009) A review on FAME production processes. Fuel 89(1):1-9

91. Meng X et al (2009) Biodiesel production from oleaginous microorganisms. Renewable Energy 34(1):1-5

92. Lewis B, Von Elbe G (1961) Combustion, flames, and explosions of gases. Academic, New York

93. Danquah MK et al (2009) Microalgal growth characteristics and subsequent influence on dewatering efficiency. Chem Eng J 151 (1-3):73-78

94. McNeff CV et al (2008) A continuous catalytic system for biodiesel production. Appl Catal, A 343(1-2):39-48

95. Powell EE, Hill GA (2009) Economic assessment of an integrated bioethanol-biodiesel-microbial fuel cell facility utilizing yeast and photosynthetic algae. Chem Eng Res Des 87 (9): $1340-1348$

96. Wang ZT et al (2009) Algal lipid bodies: stress induction, purification, and biochemical characterization in wild-type and starchless Chlamydomonas Reinhardtii. Eukaryot Cell 8 (12): $1856-1868$

97. Hu Q et al (2008) Microalgal triacylglycerols as feedstocks for biofuel production: perspectives and advances. Plant J 54 (4):621-639

98. Li Y, Qin J (2005) Comparison of growth and lipid content in three Botryococcus braunii strains. J Appl Phycol 17(6):551-556

99. Behrens P, Kyle D (1996) Microalgae as a source of fatty acids. J Food Lipids 3(4):259-272

100. Sriharan S, Bagga D, Nawaz M (1991) The effects of nutrients and temperature on biomass, growth, lipid production, and fatty acid composition of Cyclotella cryptica Reimann, Lewin, and Guillard. Appl Biochem Biotechnol 28-29(1):317-326

101. Yamaberi K, Takagi M, Yoshida T (1998) Nitrogen depletion for intracellular triglyceride accumulation to enhance liquefaction yield of marine microalgal cells into a fuel oil. J Mar Biotechnol 6(1):44-48

102. Oh SH et al (2009) Lipid production in Porphyridium cruentum grown under different culture conditions. J Biosci Bioeng 108 (5):429-434

103. Ehimen EA, Sun ZF, Carrington CG (2009) Variables affecting the in situ transesterification of microalgae lipids. Fuel 89 (3):677-684

104. Pruvost $J$ et al (2009) Investigation of biomass and lipids production with Neochloris oleoabundans in photobioreactor. Bioresour Technol 100(23):5988-5995

105. Liang Y, Sarkany N, Cui Y (2009) Biomass and lipid productivities of Chlorella vulgaris under autotrophic, heterotrophic and mixotrophic growth conditions. Biotechnol Lett 31 (7):1043-1049

106. Huntley M, Redalje D (2007) CO2 mitigation and renewable oil from photosynthetic microbes: a new appraisal. Mitig Adapt Strateg Glob Change 12(4):573-608

107. Chiu $\mathrm{S}$ et al (2009) Lipid accumulation and $\mathrm{CO}_{2}$ utilization of Nannochloropsis oculata in response to $\mathrm{CO}_{2}$ aeration. Bioresour Technol 100(2):833-838

108. Emdadi D, Berland B (1989) Variation in lipid class composition during batch growth of Nannochloropsis salina and Pavlova lutheri. Mar Chem 26(3):215-225

109. Gouveia L et al (2009) Neochloris oleabundans UTEX \#1185: a suitable renewable lipid source for biofuel production. J Ind Microbiol Biotechnol 36(6):821-826 
110. Weber RS (2009) Comments on "Thermochemical Catalytic Liquefaction of the Marine Microalgae Duanaliella tertiolecta and Characterization of Bio-oils" by Zou et al. Energy Fuels 23 (12):6275-6276

111. Jorquera $\mathrm{O}$ et al (2010) Comparative energy life-cycle analyses of microalgal biomass production in open ponds and photobioreactors. Bioresour Technol 101(4):1406-1413
112. Largeau C et al (1980) Sites of accumulation and composition of hydrocarbons in Botryococcus braunii. Phytochemistry 19 (6):1043-1051

113. Beal CM, Hebner RE, Webber ME, Ruoff RS, Seibert AF (2010) The Energy Return on Investment for Algal Biocrude: Results for a Prototype Production Pathway, ASME Congress (IMECE), IMECE2010-38244, Accepted 